\title{
Regulation of lipid signaling by diacylglycerol kinases during $T$ cell development and function
}

\section{Sruti Krishna ${ }^{1,2}$ and Xiao-Ping Zhong ${ }^{1,2 *}$}

1 Department of Pediatrics, Division of Allergy and Immunology, Duke University Medical Center, Durham, NC, USA

${ }^{2}$ Department of Immunology, Duke University Medical Center, Durham, NC, USA

\section{Edited by:}

Karsten Sauer, The Scripps Research Institute, USA

\section{Reviewed by:}

Salvatore Valitutti, INSERM, France Patrick Jerome Bertolino, Centenary Institute, Australia

\section{*Correspondence}

Xiao-Ping Zhong, Department of Pediatrics, Division of Allergy and Immunology, Duke University Medical Center, Box 2644, Durham, NC 27710, USA

e-mail:zhong001@mc.duke.edu
Diacylglycerol (DAG) and phosphatidic acid (PA) are bioactive lipids synthesized when the T cell receptor binds to a cognate peptide-MHC complex. DAG triggers signaling by recruiting Ras guanyl-releasing protein 1, PKC $\theta$, and other effectors, whereas PA binds to effector molecules that include mechanistic target of rapamycin, Src homology region 2 domaincontaining phosphatase 1, and Raf1. While DAG-mediated pathways have been shown to play vital roles in T cell development and function, the importance of PA-mediated signals remains less clear. The diacylglycerol kinase (DGK) family of enzymes phosphorylates DAG to produce PA, serving as a molecular switch that regulates the relative levels of these critical second messengers. Two DGK isoforms, $\alpha$ and $\zeta$, are predominantly expressed in T lineage cells and play an important role in conventional $\alpha \beta$ T cell development. In mature $T$ cells, the activity of these DGK isoforms aids in the maintenance of self-tolerance by preventing $T$ cell hyper-activation and promoting $T$ cell anergy. In this review, we discuss the roles of DAG-mediated pathways, PA-effectors, and DGKs in T cell development and function. We also highlight recent work that has uncovered previously unappreciated roles for DGK activity, for instance in invariant NKT cell development, anti-tumor and anti-viral CD8 responses, and the directional secretion of soluble effectors.

Keywords: diacylglycerol kinase, phosphatidic acid, $\mathrm{T}$ cell development, $\mathrm{T}$ cell activation, $\mathrm{T}$ cell tolerance, $\mathrm{T}$ cell receptor, mast cells, macrophages

\section{INTRODUCTION}

Lipids are small hydrophobic molecules that perform a variety of cellular functions. Though best known for their role in maintaining cell structure and storing energy, lipids have gained in importance over the past few decades as signaling mediators (1, 2). While lipids that participate in signaling are thought to be much less abundant in the cell as compared to structural lipids, their levels vary dynamically in response to external signals.

In this review, we discuss the signaling functions of two key lipid second messengers, diacylglycerol (DAG) and phosphatidic acid (PA), in the context of T cell development and function. DAGs are esters of glycerol in which two of its hydroxyl groups are esterified with long-chain fatty acids. One manner of PA generation in cells is via phosphorylation of the free hydroxyl group in DAG by a family of enzymes called diacylglycerol kinases (DGKs) $(3,4)$. DGKs therefore act as molecular switches that simultaneously turn off DAG-mediated signaling and turn on PA-mediated signals.

While all 10 mammalian DGK isoforms contain a kinase domain and at least two cysteine-rich $\mathrm{C} 1$ domains, they can be grouped into five types based on the homology of their other structural features. $\alpha$ and $\zeta$ are the major isoforms expressed in $\mathrm{T}$ cells (5). DGK $\alpha$ is a type I DGK and contains an $\mathrm{N}$-terminal recoverin homology domain and two $\mathrm{Ca}_{2}{ }^{+}$-binding $\mathrm{EF}$ hands. DGK $\zeta$ is a type IV DGK and contains a myristoylated alanine rich C kinase substrate (MARCKS) motif, four ankyrin repeats and a C-terminal PDZ-binding domain. DGKל undergoes alternative splicing, producing a $130 \mathrm{kDa} \zeta 2$ isoform that is highly expressed in immature thymocytes and a $115 \mathrm{kDa} \zeta 1$ isoform that is predominant in mature thymocytes and peripheral T cells (6). Functional differences between the two splice variants remain unclear.

Here, we begin by discussing the various effector molecules that transduce DAG-mediated signals and PA-mediated signals. We then switch gears to review our current understanding of the role of DGKs in T cell development and function with an emphasis on recent advances that have revealed hitherto unknown functions for these enzymes. The roles of DGK activity in other immune cell lineages are also discussed briefly.

\section{DAG-MEDIATED SIGNALING}

Several enzymes contribute toward DAG production upon receptor stimulation in immune cells (7) (Figure 1). Phosphatidylinositol-dependent phospholipases hydrolyze membrane phosphatidylinositol bisphosphate $\left(\mathrm{PIP}_{2}\right)$ to DAG and inositol triphosphate, and phosphatidylcholine (PC)-dependent phospholipases hydrolyze PC to DAG and phosphoryl choline. In addition, sphingomyelin synthase generates DAG and sphingomyelin from PC and ceramide, while PA phosphatases such as lipins dephosphorylate PA to DAG. On the other hand, DAG is primarily removed by the activity of DGKs, which catalyze its phosphorylation to PA. DAG can recruit a variety of downstream effector molecules through their $\mathrm{C} 1$ domains, and thereby trigger multiple signaling pathways.

The protein kinase C (PKC) family of serine/threonine kinases consists of 10 isozymes that are activated by a number of distinct 


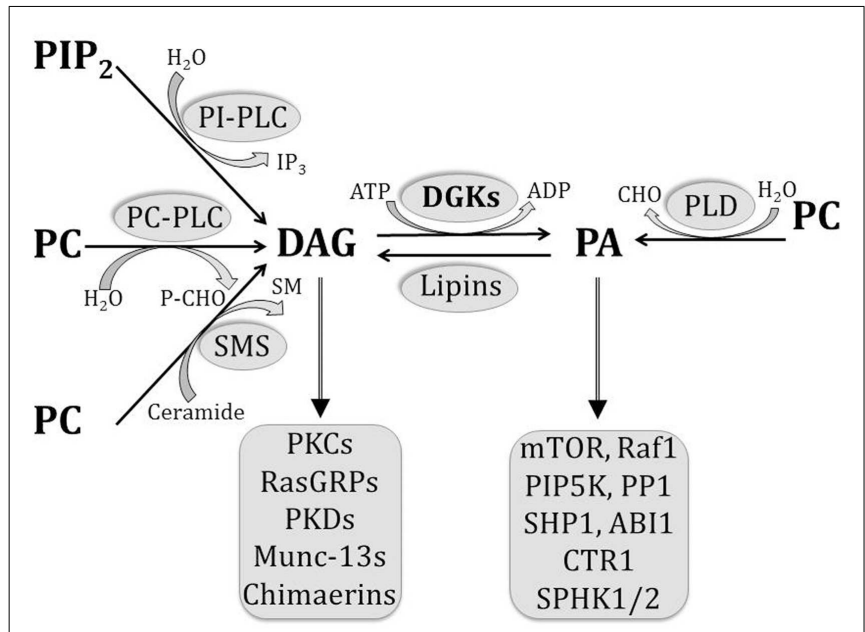

FIGURE 1 | Pathways involved in the generation and removal of DAG and PA. Multiple pathways contribute to DAG generation in the cell, including the hydrolysis of $\mathrm{PIP}_{2}$ by $\mathrm{PI}$-dependent PLCs, hydrolysis of $\mathrm{PC}$ by PC-dependent PLCs, dephosphorylation of PA by lipins, and sphingomyelin synthesis by SMS. On the other hand, PA is generated by PLD-mediated hydrolysis of PC and by DGK-mediated phosphorylation of DAG. As bioactive lipids, both DAG and PA are able to bind to a number of effector molecules, as listed.

mechanisms $(8,9)$. Upon engagement of the TCR, production of DAG by activated PLC $\gamma 1$ recruits PKC $\theta$ to the plasma membrane in T cells. Co-stimulation via CD28 also plays an important role in the recruitment and spatial segregation of $\mathrm{PKC} \theta$ at the immunological synapse $(10,11)$. Activation of $\mathrm{PKC} \theta$ is indispensable for TCR-mediated NF- $\kappa \mathrm{B}$ activation in mature T cells $(12,13)$. A role for PKC $\theta$ has also been identified in an array of key processes (14) including invariant NKT $(i \mathrm{NKT})$ cell development and activation $(15,16), \mathrm{T}$ cell survival (17), IL-2 production (18), $\mathrm{T}_{\mathrm{H}} 2$ responses $(19,20)$, and $\mathrm{T}_{\mathrm{H}} 17$ responses $(21)$. Thus, by recruiting PKC $\theta$, DAG regulates multiple aspects of $\mathrm{T}$ cell function.

Another important protein that is brought to the plasma membrane by DAG upon TCR stimulation is Ras guanyl-releasing protein 1 (RasGRP1) (22). RasGRP1 is a member of the RasGRP family of factors that help activate Ras by exchanging bound GDP for GTP (23), and is selectively expressed in T cells and a few other cell types (24). RasGRP1 plays an essential role in thymocyte development (25), and is particularly required for the selection of thymocytes that express weakly selecting TCRs (26). RasGRP1 is not critical for the development of $\gamma \delta \mathrm{T}$ cells, but is important for their proliferation and IL-17 production (27). Other studies have shown that RasGRP1 may play a role in promoting antigeninduced CD8 cell expansion by lowering the threshold of T cell activation (28). RasGRP1 is therefore a key effector downstream of DAG that plays a multitude of critical roles in T cell development and function.

Members of the protein kinase D (PKD) family have been identified more recently as DAG effectors (29). A unique characteristic of PKDs is that they are targets of both DAG and DAG-activated PKCs (30). PKDs are thought to be activated by a multi-step mechanism. Upon cell stimulation, inactive PKD translocates from the cytosol to the plasma membrane in response to membrane DAG production, where it is then activated by novel PKCs that are also recruited to the membrane by DAG. During T cell development, PKD has been shown to exert different effects on VDJ recombination at the TCR $\beta$ locus and on CD4 and CD8 expression, based on its localization at the cytosol or plasma membrane (31). Subsequent work has revealed that regulation of thymocyte development by membrane-localized PKD, but not cytosol-localized PKD, is dependent on the GTPase RhoA (32). Bringing PKD to the plasma membrane therefore represents another important mechanism by which DAG regulates T cell development.

Munc13 proteins are mammalian homologs of the C. elegans Unc13 that is localized to pre-synaptic active zones of neurons and important for neurotransmitter secretion (33). Munc13-1, Munc13-2, and Munc13-3 isoforms bind to DAG with high affinity, and translocate to the plasma membrane in response to receptor stimulation. In the immune system, the Munc13-4 isoform which lacks a $\mathrm{C} 1$ domain $(34,35)$ has been shown to be important for granule maturation and exocytosis in NK cells and cytotoxic T lymphocytes (CTLs) $(36,37)$, and for phagosomal maturation and killing of intracellular bacteria in neutrophils $(38,39)$. Further studies are required to investigate parallel roles for DAG-binding Munc13 isoforms in NK cells, CTLs, neutrophils, and other types of immune cells. Over-expressing human Munc13 in opossum renal epithelial cell lines enhanced their susceptibility to apoptosis after DAG treatment, suggesting that Munc13 proteins may transduce apoptosis-inducing signals downstream of DAG in some cell types (40). The role of Munc13 proteins in T cell development and function remain poorly understood.

Chimaerins, a family of proteins that possess Rac-specific GTPase Activating Protein (GAP) activity, contain C1 domains that bear about 40 percent homology to those of PKCs $(41,42)$. Chimaerin isoforms $\alpha 2$ and $\beta 2$ are expressed at different levels in $\mathrm{T}$ cells and have been shown to participate in TCR signaling (43). Results from the study suggest that these chimaerin isoforms translocate to the immunological synapse upon T cell activation, but in a manner that is independent of canonical DAG-binding by the $\mathrm{C} 1$ domains. Catalytic activity of these chimaerins was found to play an important role in inhibiting TCR-mediated NFAT activation. Other studies have delineated a role for $\beta 2$ chimaerin in mediating DAG-dependent changes in T cell adhesion and chemotaxis (44). In this study, expression of GFP-tagged $\beta 2$ chimaerin revealed that active Rac and C1-dependent PMA binding could co-operate to induce sustained localization of $\beta 2$ chimaerin to the plasma membrane in Jurkat T cells. Overexpression of GFP- $\beta 2$ chimaerin was associated with decreased CXCL12-induced static adhesion but enhanced CXCL12-induced migration. Chimaerin proteins therefore represent an important class of DAG effectors in T cells, but further work is required to dissect aspects of their function that are dependent on and independent of DAG-binding.

\section{PA-MEDIATED SIGNALING}

Diacylglycerol kinases and enzymes of the phospholipase D (PLDs) family act as key mediators of PA production in immune cells by phosphorylating DAG and hydrolyzing PC, respectively $(7,45)$ (Figure 1). On the other hand, enzymes such as lipins that possess PA phosphatase activity play a critical role in turning off 
PA-mediated signaling by removing PA (46). Cellular levels of PA have been shown to change dynamically in response to environmental stimuli, and a wealth of data has revealed a diverse array of functions for this bioactive lipid (47).

Phosphatidic acid performs its signaling functions primarily by associating with a growing number of effector molecules that include kinases such as mammalian/mechanistic target of rapamycin (mTOR) and phosphatidylinositol-4-phosphate 5kinase (PIP5K), and phosphatases such as Src homology region 2 domain-containing phosphatase 1 (SHP1) (48). In mammalian HEK293 cells, treatment with exogenous PA was found to promote the phosphorylation of S6K1 and 4E-BP1, which are substrates of mTOR complex 1 (49). This phosphorylation was abolished by rapamycin, a bacterial macrolide that inhibits mTOR activity. Results from this study showed that mitogenic stimulation of HEK293 cells led to cellular PA accumulation within $5 \mathrm{~min}$. Small unilamellar vesicles containing PA could also directly bind to the FKBP12-rapamycin binding (FRB) domain on mTOR in a manner that competed with FKBP12-rapamycin. Together, these results suggest a role for PA as a critical mediator that connects mitogenic stimuli to mTOR activation in mammalian cells (50). More recent work has revealed that PA may activate mTOR by a distinctive two-step mechanism that involves the displacement of the endogenous mTOR-inhibitor FKBP38 and allosteric activation of the kinase (51). On the other hand, studies with Rat2 fibroblasts suggest that PA may indirectly activate mTOR complex 1 via the MEK-ERK pathway (52). In this study, two structurally distinct MEK inhibitors were found to inhibit PA-mediated activation of mTOR complex 1 . Other studies with human renal cell adenocarcinoma cell lines have shown that suppression of cellular PA production by treatment with a PLD inhibitor may inhibit the association of mTOR with both Raptor and Rictor, suggesting that PLD-derived PA may act as a key stabilizer of mTOR complexes 1 and 2 (53).

Diacylglycerol kinase-derived PA has also been shown to modulate mTOR complex 1 activity in HEK293 cell lines (54). Overexpression of DGK $\zeta$, but not DGK $\alpha$, led to increased mTOR complex 1-dependent phosphorylation of S6K1 both in the presence and absence of serum, suggesting that DGK $\zeta$-derived PA may activate mTOR complex 1 . DGK $\zeta$-induced S6K1 phosphorylation was dose-dependent, as cells expressing higher levels of DGK $\zeta$ showed more intense S6K1 phosphorylation. DGK $\zeta$-mediated increase in S6K1 phosphorylation was abolished when a mutant form of mTOR (that lacked the capacity to bind PA) was co-expressed, suggesting that $\mathrm{DGK} \zeta$-generated $\mathrm{PA}$ enhances $\mathrm{S} 6 \mathrm{~K} 1$ phosphorylation by directly binding to mTOR.

While it is tempting to extend these observations to suggest that PA may directly bind and activate mTOR in immune cells, only a few studies have rigorously examined the relationship between PA and mTOR in these cell types. RAW264.7 macrophage cell lines showed enhanced secretion of pro-inflammatory cytokines such as IL-6, TNF- $\alpha$, and IL- $1 \beta$ in response to PA stimulation (55). This was specifically abrogated by rapamycin, suggesting that PA-induced production of pro-inflammatory cytokines in macrophages may occur through the mTOR complex 1 pathway. Treatment of mice with PA also led to an increase in serum levels of these cytokines, suggesting that PA may promote systemic inflammatory responses in a manner that is dependent on mTOR complex 1 activation.

As we discuss later in this review, a bevy of studies provide clear genetic evidence of critical roles for DGK $\alpha$ and DGK $\zeta$ in multiple aspects of $\mathrm{T}$ cell maturation and function. However, much work remains to be done in understanding the role of DGK-derived and PLD-derived PA in activating mTOR complex 1 during T cell development and function.

Another key signaling pathway that is activated by PA is the Ras/MEK/ERK signaling cascade (56). The first line of evidence for PA-mediated modulation of MAP kinase signaling came from a study which showed that a C-terminal domain of Rafl could bind to PA in a canine kidney cell line (57). Subsequent work showed that growth factor-mediated activation of PLD and the concomitant production of PA were directly linked to the activation of the Raf1-MAP kinase pathway (58). Based on findings that insulin-dependent PLD activation was critically dependent on ADP ribosylation factor (ARF) activation, the researchers used an ARF inhibitor (brefeldin A) to block PLD activation (59). Blocking PLD activity and PA production with brefeldin A blocked insulin-induced activation of the MAPK pathway in Rat-1 fibroblasts. Results from the study also showed that PA did not directly activate Raf1, but instead enhanced its recruitment to the plasma membrane to allow for its activation by Ras. Mutations in Raf1 that disrupted Raf1-PA interaction prevented plasma membrane recruitment of Raf1 in response to insulin stimulation (60).

Kinase suppressor of Ras 1 (KSR1) is a scaffolding protein that interacts with several components of the Raf-MEK-ERK cascade to co-ordinate the formation of localized multi-protein complexes that enable efficient signal transduction (61). More recent work has shown that KSR1 contains a sequence homologous to Raf1's PA-binding domain that allows it to directly bind PA and be recruited to the plasma membrane in response to insulin stimulation in fibroblasts (62). The recruitment of KSR1 by PA was also found to be essential for its scaffolding function, as mutations in its PA-binding motif impaired insulin-induced MEK and ERK phosphorylation. Studies have shown that PA also recruits Sos, an activator of Ras, to the plasma membrane through its plextrin homology domain (63). PLD2-derived PA was found to play essential role in EGF-induced Ras activation, as mutations of Sos that impaired PA-binding prevented its membrane recruitment and subsequent activation of Ras.

Studies with Jurkat T cells suggest that PLD2 may act upstream of RasGRP1 upon TCR crosslinking and co-stimulation via the integrin lymphocyte function-associated antigen 1 (LFA1) (64). In this case, production of PA by PLD2 and subsequent dephosphorylation of PA to DAG by PA phosphatase were shown to be critical for plasma membrane Ras activation. Others have demonstrated a role for PLD-derived PA in ERK1/2 activation downstream of Galectin-8 engagement in Jurkat T cells (65). Galectins are a family of widely expressed carbohydrate-recognizing proteins, and Gal-8 has previously been shown to bind certain integrins on the $\mathrm{T}$ cell surface to provide co-stimulatory and proliferative signals (66). In this study, Gal-8 induced PA accumulation in Jurkat T cells within $15 \mathrm{~min}$ in a manner that was inhibited by treatment with a PLD inhibitor (1-butanol). Such PLD-inhibition also abrogated ERK1/2 phosphorylation, suggesting that PLD-derived PA 
may play an essential role in ERK activation downstream of Gal-8 stimulation in Jurkat T cells. However, this result must be interpreted with caution, as PLD-derived PA may also activate ERK in an indirect manner involving the lipin-mediated conversion of PA to DAG.

Type I PIP5K enzymes catalyze the production of $\mathrm{PIP}_{2}$ from phosphatidylinositol-4-phosphate (PIP). During T cell activation, $\mathrm{PIP}_{2}$ is involved in modulating $\mathrm{T}$ cell rigidity but is primarily hydrolyzed to produce key second messengers DAG and inositol triphosphate $\left(\mathrm{IP}_{3}\right)(51)$. A number of studies have established that PA can bind to and activate PIP5K (67). Modulation of PIP5K activity by PA was originally shown using PIP5K purified from bovine brain membranes, where PA was shown to enhance enzymatic activity by up to 20-fold (68). Subsequent studies demonstrated that type I PIP5Ks (which phosphorylate PIP to $\mathrm{PIP}_{2}$ ), but not type II PIP5Ks (which phosphorylate phosphatidylinositol 5 phosphate to $\mathrm{PIP}_{2}$ ), are specifically regulated by PA (69). More recent work has suggested that PA may regulate the affinity of murine PIP5K-1 $\beta$ for its substrate PIP (70). In this study, PA was shown to bind specifically to the C-terminal region of PIP5K-1 $\beta$ and kinetic analysis revealed that the addition of PA increased the affinity of PIP-binding to the enzyme's active site by nearly 70 -fold. Other studies have elegantly demonstrated a role for DGK $\zeta$-derived PA in stimulating PIP5K-1 $\alpha$ activity to increase local $\mathrm{PIP}_{2}$ levels and promote actin polymerization in cell lines (71). Expression of DGK $\zeta$ enhanced PIP5K-1 $\alpha$ activity in thrombin-stimulated HEK293 cells, and DGK $\zeta$ and PIP5K-1 $\alpha$ were found to co-localize and co-immunoprecipitate with each other. DGK $\zeta$ and PIP5K-1 $\alpha$ were also found to co-localize with actin at lamellipodial protrusions in epithelial cells. While there is evidence to suggest that the activity of PIP5K-1 $\alpha$ and $\gamma$ isoforms may be critical for normal human NK cell cytotoxicity $(72,73)$, the role of PLD-derived and DGK-derived PA in regulating PIP5K activity in immune cells remains quite poorly understood.

Protein phosphatase 1 (PP1) is a eukaryotic serine/threonine phosphatase that regulates the function of a variety of proteins in the cell. The PP1 catalytic subunit is able to interact with more than 50 different regulatory subunits in a mutually exclusive manner and this allows the enzyme to target different substrates in diverse subcellular locations depending on its binding partner (74). Initial studies identified that PA acted as a highly specific tight-binding inhibitor of the $\gamma$ isoform of human PP1 in vitro (75). Further studies used a deletion mutagenesis approach to reveal that residues 286-296 of PP1 $\gamma$ were necessary and sufficient for PA-binding (76). Results from one study suggest that PP1 activity may play a role in suppressing $\mathrm{T}$ cell function in a rat model of alcohol intoxication and burn injury (77). While this suggests that PA-mediated inhibition of PP1 function may facilitate T cell activation, further experiments are required to better understand the role of PLD-derived and DGK-derived PA in suppressing PP1 activity in T cells.

Src homology region 2 domain-containing phosphatase 1 is a tyrosine phosphatase that plays a critical role in $\mathrm{T}$ cell function (78). "Moth-eaten" mice carry a spontaneous frame-shift mutation in the SHP1 gene and lack detectable SHP1 protein (79). Studies with these mice revealed a role for SHP1 in negatively regulating positive and negative thymocyte selection (80), while the use of conditional SHP1 knockout mice showed that SHP1 limits the number of short-lived effector CD8 cells produced in response to viral infection (81). Early studies showed that PA could increase the phosphatase activity of SHP1 toward the EGF receptor when the two proteins were transiently co-expressed in 293 cells (82). Subsequently, PA was shown to directly bind to recombinant SHP1, and two distinct PA-binding sites (a high affinity site on the Cterminal end and a low affinity site on the N-terminal end) were identified on SHP1 (83). Future studies are required to determine if PA modulates SHP1 activity in immune cells and if PA may serve as an effective therapeutic agent to modulate immune responses.

\section{ROLE OF DGK ACTIVITY IN THYMOCYTE DEVELOPMENT}

Bone marrow-derived early progenitor cells must go through an elaborate process of development in the thymus to become mature $\mathrm{T}$ cells $(84,85)$. Thymocytes at different stages of maturation are readily distinguished by a combination of CD4 and CD8 coreceptors expressed on their cell surface, proceeding from the earliest stage with neither CD4 nor CD8 (double negative/DN) through an intermediate stage expressing both CD4 and CD8 (double positive/DP) to a mature stage marked by the expression of either CD4 or CD8 (CD4 single positive/CD4SP or CD8 single positive/CD8SP $(86,87)$. While progenitor cells enter the thymus at the cortico-medullary junction, a number of sequential chemokine/chemokine-receptor interactions help guide a developing thymocyte through the thymic cortex and medulla, facilitating its progressive relocation to appropriate micro-environments within the thymus $(88,89)$.

With the expression of RAG proteins, DN cells undergo VDJ recombination at the TCR $\beta$ locus, expressing a pre-TCR on the cell membrane. DN cells with a productive TCR $\beta$ rearrangement pass through the $\beta$-selection developmental checkpoint, undergoing multiple rounds of proliferation and upregulating expression of CD4 and CD8 to become DP cells. DP cells subsequently rearrange $\mathrm{V}$ and $\mathrm{J}$ genes at the TCR $\alpha$ locus, expressing a unique TCR on the cell surface. Subsequently, cells bearing TCRs that recognize self-peptide-MHC complexes on thymic epithelial cells receive survival signals during the so-called positive selection process, while others that fail to recognize these complexes die of "neglect" $(90,91)$. On the other hand, DP cells with TCRs that recognize self-peptide-MHC complexes with high affinity are eliminated by apoptosis-inducing signals during negative selection $(92,93)$. Together, positive and negative selection processes ensure the generation of a $\mathrm{T}$ cell repertoire that is both functional and self-tolerant $(94,95)$. DP cells that survive these selection processes mature into CD4SP and CD8SP cells that eventually migrate to secondary lymphoid organs as naïve CD4 and CD8 T cells $(96,97)$.

A plethora of studies have implicated DAG-dependent signaling pathways in $\beta$, positive and negative selection. For instance, early studies showed that signaling via the pre-TCR activates ERK1/2 (98), while more recent ones have demonstrated an essential role for RasGRP1 and ERK activation in efficient $\beta$-selection $(27,99)$. Mice with a T cell-specific deficiency of PLC $\gamma 1$ show dramatically reduced numbers of mature CD4SP and CD8SP thymocytes, and defects in both positive and negative selection when crossed with HY TCR transgenic mice (100). Impairment 
of thymic selection in the absence of PLC $\gamma 1$ suggests that its product DAG may play an important role in the process. Lending further credence to this notion, RasGRP1-deficient mice show impaired Ras-ERK signaling in thymocytes and defective thymic selection with a $70-90 \%$ reduction of mature SP cells $(25,26)$. Transgenic mice expressing a dominant negative form of Ras present with defects in positive selection, but not negative selection, when crossed with HY TCR transgenic mice (101). Similar observations were made with transgenic mice that expressed a catalytically inactive form of MEK1 (K97A) under the control of the thymocyte-specific Lck proximal promoter (102). ERK1 deficiency results in a severe developmental block at the DP stage (103). Conditional deletion of ERK2 using proximal Lck-Cre partially blocked DN3 to DN4 progression, while deletion with CD4-Cre led to defective positive selection. Mice with a combined deficiency of ERK1 and ERK2 showed that ERK activity is required for proliferation and differentiation associated with $\beta$-selection, and for positive selection (104). The MAP kinase-interacting serine/threonine kinases (Mnks) 1 and 2 lie downstream of ERK1/2 and p38 $(105,106)$. Recent studies have shown that TCR triggering can activate Mnk1/2 via the Ras-ERK pathway in a manner that is negatively regulated by DGK $\alpha \zeta$ activity (107). Although Mnk1/2 phosphorylate EIF4E, which is thought to promote translation initiation, combined deficiency of Mnk1/2 did not lead to obvious changes in thymocyte development. The mechanisms by which ERK1/2 regulate thymocyte selection remain to be clearly defined. Together, these studies suggest that the DAGRasGRP1-Ras-ERK pathway plays a critical role in thymocyte development.

The role of the DAG-mediated PKC $\theta-I K K-N F-\kappa B$ pathway in $\mathrm{T}$ cell development has also been studied extensively. While initial studies found no obvious developmental defects in PKC $\theta$ deficient thymocytes, more recent ones have suggested that PKC $\theta$ may be required for efficient positive selection $(108,109)$. T cell-specific deletion of IKK $\gamma$ or replacement of IKK $\beta$ with a dominant kinasedead form results in a reduction of mature CD8SP cells (110), while transgenic models that allow for activation or inhibition of NF- $\kappa \mathrm{B}$ have revealed its role in the establishment of signaling thresholds for positive and negative selection (111).

The importance of these DAG-mediated pathways suggests that their tight regulation by DGK may be critical for normal thymocyte development. Studies with mice that lack both DGK $\alpha$ and DGK $\zeta$ (DGK $\alpha \zeta$ DKO) have confirmed this hypothesis (112). DGK $\alpha \zeta$ DKO thymocytes experience excessive DAG accumulation and enhanced DAG-mediated signaling after TCR engagement. This is associated with a severe developmental block at the DP stage and a marked paucity of mature CD4SP and CD8SP cells. Defects in positive, but not negative, selection were revealed using a $\mathrm{HY}$ TCR transgenic system. Addition of exogenous PA to fetal thymic organ cultures increased the frequency of SP cells in DGK $\alpha \zeta \mathrm{DKO}$ thymi without obvious effects on control thymi, suggesting that DGK $\alpha$ and DGK $\zeta$ play a synergistic role in T cell development not just by dampening DAG-mediated signals but also by promoting PA-mediated signals. This DGK-induced switch from DAG-driven to PA-driven signals may also play a critical role in preventing prolonged activation of the highly oncogenic Ras-ERK and NF- $\mathrm{B}$ pathways in developing thymocytes. Indeed, HY TCR transgenic mice with decreased DGK activity showed significantly enhanced thymic lymphomagenesis, suggesting an important role for DGK activity in tumor suppression (112).

More recent work from our group has uncovered a novel role for DGKs as negative regulators of mTOR activity in thymocytes (113). Results from the study showed that low concentrations of phorbol 12-myristate 13-acetate (PMA), a functional analog of DAG, were able to induce phosphorylation of mTOR complex 1 substrates S6K1 and 4E-BP1 and mTOR complex 2 substrate Akt (S473), suggesting that DAG-mediated signaling is sufficient to induce activation of both mTOR complexes in thymocytes. DGK $\alpha \zeta D K O$ thymocytes showed enhanced phosphorylation of S6K1, 4E-BP1, and Akt (S473) upon TCR engagement as compared to WT counterparts, suggesting that DGK activity inhibits TCRinduced activation of mTORc1 and mTORc2. Further studies are required to determine if dysregulated mTOR signaling might contribute to the defects in T cell development and function observed in DGK $\alpha \zeta \mathrm{DKO}$ mice.

Emerging evidence also suggests that tight regulation of DAGmediated signaling by DGK activity may be critical for the development of $i$ NKT cells. $i$ NKT cells are a rare but distinct lineage of $\alpha \beta$ T cells that express a highly restricted TCR repertoire and recognize glycolipids presented on CD1d. Sometimes called the "Swiss-Army knife" of the immune system, $i$ NKT cells bridge innate and adaptive immunity by performing an array of functions that include killing of infected cells and secretion of cytokines and chemokines (114). Despite their relative rarity, an important role for $i$ NKT cells has been demonstrated in immune responses to pathogens, allergens, self-antigens, and cancer.

Previous work has revealed a critical role for signaling via the PKC $\theta-I K K-N F-\kappa B$ pathway in the ontogeny of $i$ NKT cells (15, 115-117). More recent studies have identified that RasGRP1-RasERK signaling may also be indispensable for $i$ NKT development. In one study, the absence of RasGRP1 was associated with a severe reduction of $i$ NKT cell numbers in the thymus, spleen, and liver (118). The generation of bone marrow chimeras showed that the $i$ NKT cell developmental defects were cell-intrinsic, and the remaining RasGRP1-deficient iNKT cell population displayed both a selective absence of $\mathrm{CD} 4^{+}$cells and defects in TCR-induced proliferation. In another study, the expression of a dominant negative form of Ras dramatically hindered $i \mathrm{NKT}$ development (118, 119).

While lack of IKK-NF- $\kappa \mathrm{B}$ and Ras-ERK signaling is detrimental to $i$ NKT cell development, recent findings indicate that hyperactive signaling via these DAG-mediated pathways may also perturb $i$ NKT development (120). In this study, T lineage specific expression of a constitutively active form of Ras resulted in a late stage block in $i$ NKT cell maturation, and constitutively IKK $\beta$ activity was associated with increased cell death at multiple developmental stages. Since the maintenance of optimal levels of DAG-mediated signaling appears to be essential for normal $i$ NKT development, we hypothesized that tight regulation of DAG-mediated signals by DGK activity might be essential for this process. Results from our studies showed that while $i \mathrm{NKT}$ cell numbers were unaltered in mice lacking either DGK $\alpha$ or DGK $\zeta$, they were dramatically diminished in DGK $\alpha \zeta \mathrm{DKO}$ counterparts, suggesting that these DGK isoforms may play a redundant role in regulating $i \mathrm{NKT}$ cell 
development (120). Defective DGK $\alpha \zeta \mathrm{DKO} i \mathrm{NKT}$ development was associated with enhanced cell death and co-incident with enhanced activation of the Ras-ERK and NF- $\kappa$ B pathways. Taken together, these results suggest that DGK $\alpha$ and DGK $\zeta$ work synergistically to maintain an optimal level of DAG-mediated signaling that is essential for normal $i$ NKT development.

\section{ROLE OF DGK ACTIVITY IN T CELL FUNCTION DGK $\alpha$ AND DGKל IN T CELL ACTIVATION}

$\mathrm{T}$ cell activation is a dynamic cellular process that involves the activation of multiple signaling cascades (Figure 2). The termination of such signaling, however, is important to prevent unrestrained immune responses and the development of autoimmunity. Research over the last decade has delineated a role for DGK $\alpha$ and DGK $\zeta$ isoforms as molecular brakes that terminate DAGmediated signals after TCR engagement. Early studies demonstrated that DGK $\zeta$ is expressed in multiple lymphoid organs, with high levels in the $\mathrm{T}$ cell compartment (6). Overexpression of DGK $\zeta$ in Jurkat $\mathrm{T}$ cells indicated that it substantially hindered TCR-induced Ras-ERK activation and upregulation of the activation marker CD69. DAG-binding and kinase domains, but not the ankyrin repeats, of DGK $\zeta$ were found to be required for these inhibitory effects. Analysis of germline DGK $\zeta$ knockout mice revealed no dramatic differences in $\mathrm{T}$ cell development or homeostasis (121). However, DGK $\zeta$-deficient T cells showed enhanced Ras-ERK activation and diminished PA production upon TCR engagement. Complementing observations from the Jurkat system, DGK $\zeta$-deficiency resulted in increased upregulation of CD69 and CD25 (markers of T cell activation) upon TCR engagement. Consistent with enhanced activation, DGK $\zeta$ KO $\mathrm{T}$ cells were hyper-proliferative in response to both antigenic stimulation and lymphopenia.

The role of DGK $\alpha$ in controlling $\mathrm{T}$ cell activation largely parallels that of its $\zeta$ counterpart. Overexpression of DGK $\alpha$ in Jurkat cells greatly impaired TCR-induced activation of a cotransfected AP1 driven luciferase reporter construct without obvious effects on calcium influx (122). While DGK $\alpha$ KO mice did not present with obvious changes in T cell development or homeostasis, enhanced Ras-ERK activation and hyper-proliferation were observed upon TCR engagement in DGK $\alpha$ KO T cells. Taken together, these results suggest that DGK $\alpha$ and DGK $\zeta$ act in a non-redundant manner to restrain DAG-mediated signaling and prevent $\mathrm{T}$ cell hyper-activation upon TCR engagement. Further studies are required to better understand the unique mechanisms by which these isoforms act.

\section{DGK $\alpha$ AND DGK $\zeta$ IN T CELL ANERGY}

Mechanisms of central and peripheral tolerance play a critical role in preventing the development of autoimmunity $(123,124)$. $\mathrm{T}$ cell anergy is a form of peripheral tolerance whereby $\mathrm{T}$ cells that

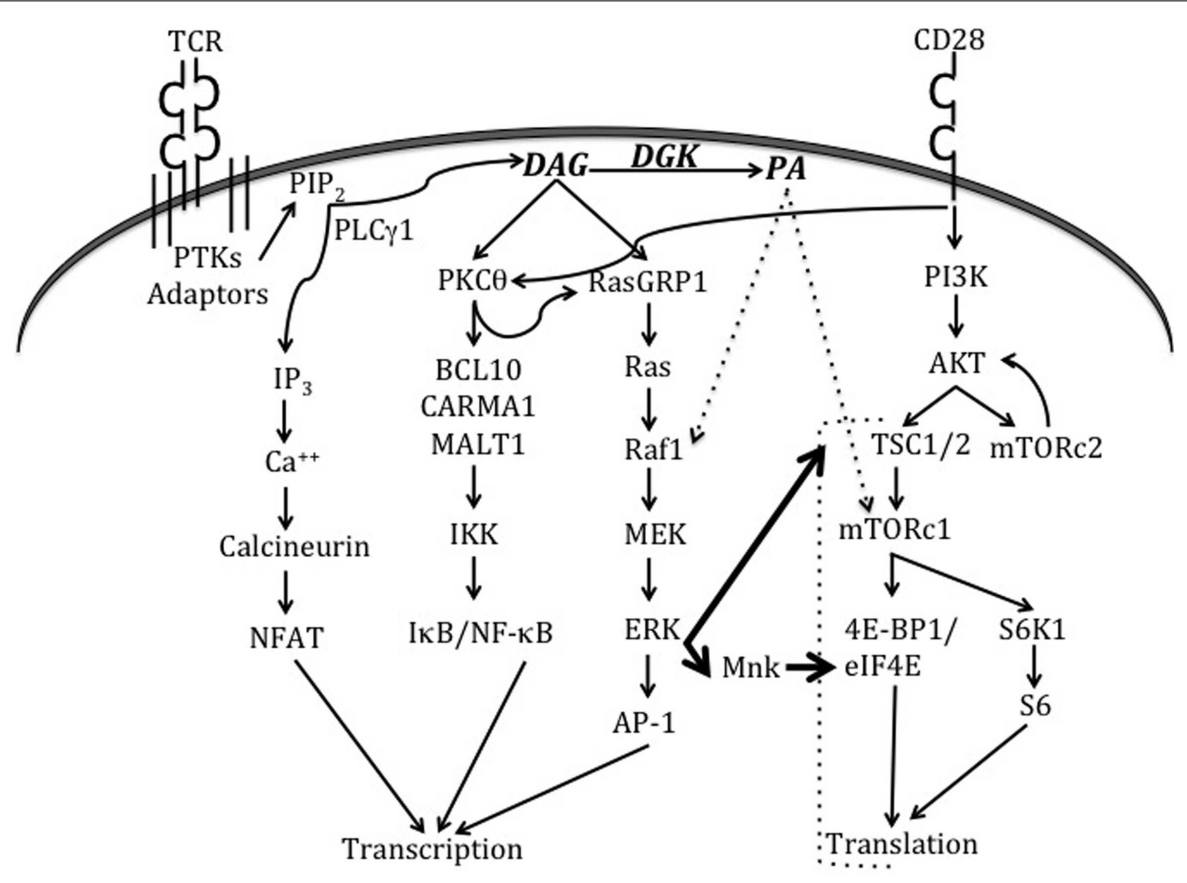

FIGURE 2 | Signaling pathways triggered by TCR and CD28 engagement. When the TCR engages a cognate peptide-MHC complex in the presence of appropriate co-stimulatory signals, this activates TCR proximal tyrosine kinases (PTKs) and results in the recruitment of a number of adaptor molecules. Eventually, the activation of PLC $\gamma 1$ enables it to hydrolyze membrane PIP $P_{2}$ to form second messengers $I_{3}$ and $D A G$. IP activates the calcineurin-NFAT pathway, while DAG activates the Ras-ERK-AP1 and NF-KB pathways. DGKs dampen DAG-mediated signals by converting DAG to PA. CD28 engagement plays an important role in the activation of PKC $\theta$ and the PI3K-Akt-mTOR axis. Recent work (indicated by thick arrows) has shown that TCR signaling can also directly activate mTOR complexes via the Ras-ERK pathway, and that such activation is negatively regulated by DGK activity. ERK can also activate Mnk1/2 kinases that phosphorylate elF4E to promote translation. PA is produced in T cells by the action of both DGKs and PLDs (not shown in this figure). In other cell types, PA has been shown to activate Raf1 and mTORc1. Please refer to the text for more details about TCR-triggered signaling pathways and effector molecules that bind to DAG or PA. 
recognize self-antigen in the absence of co-stimulatory signals are rendered functionally inactive (125-128).

While anergic T cells express elevated levels of DGK $\alpha$ as compared to naïve counterparts, levels of DGK $\zeta$ increase or remain unchanged depending upon the experimental system (122, 129, 130). Transduction of resting Coxsackievirus and adenovirus receptor $(\mathrm{CAR})$ transgenic $\mathrm{T}_{\mathrm{H}} 1$ cells with $\mathrm{DGK} \alpha$ or $\mathrm{DGK} \zeta$ containing adenoviral constructs revealed that overexpression of DGK $\alpha$, but not DGK $\zeta$, was sufficient to cause an anergy-like state (130). $\mathrm{T}_{\mathrm{H}} 1$ cells transduced with the $\mathrm{DGK} \alpha$ construct showed diminished ERK activation and IL-2 production in response to stimulation with anti-CD3 and anti-CD28. Experiments with RAG2-deficient 2C TCR transgenic cells also indicated that DGK $\alpha$ overexpression resulted in impaired recruitment of RasGRP1 to the plasma membrane. Brief treatment of anergic $\mathrm{T}_{\mathrm{H}} 1$ cells with a pharmacological inhibitor of DGK activity before overnight restimulation with anti-CD3 and anti-CD28 led to a dose-dependent increase in IL-2 production, suggesting a causal function for high DGK activity in T cell anergy. Similar results were obtained with RAG2-deficient 2C TCR transgenic T cells that had been rendered anergic in vivo.

Genetic evidence for the role of DGK $\alpha$ activity in T cell anergy comes from an in vivo anergy induction model in which mice were injected with the super-antigen staphylococcal enterotoxin B (SEB) that renders $\mathrm{V} \beta 8^{+} \mathrm{T}$ cells anergic (122). When re-stimulated with SEB exvivo, in contrast to WT counterparts, $\mathrm{V} \beta 8^{+} \mathrm{T}$ cells from DGK $\alpha$ KO mice retained the ability to produce IL-2 and proliferate. These findings complement the data from the adenoviral-based over-expression studies, and confirm that DGK $\alpha$ is essential for anergy induction in vivo.

Further studies also indicate that DGK $\alpha$ and DGK $\zeta$ may play synergistic roles in anergy induction (122). When splenocytes from WT, DGK $\alpha \mathrm{KO}$, and DGK $\zeta \mathrm{KO}$ mice were depleted of CD8 cells and stimulated in the presence of anti-CD3 and CTLA4-Ig (to block co-stimulatory signals), DGK $\alpha \mathrm{KO}$, and DGK $\zeta \mathrm{KO} \mathrm{T}$ cells underwent 2-3 rounds of proliferation in contrast to WT counterparts that did not divide. Proliferation of DGK $\zeta$ KO T cells under similar culture conditions was highly enhanced by the addition of a DGK $\alpha$ inhibitor, and was comparable to that of WT cells stimulated with anti-CD3 and anti-CD28. These results support the notion that $\alpha$ and $\zeta$ DGK isoforms may act in a synergistic manner to induce $T$ cell anergy.

\section{ROLE AND REGULATION OF DGK $\alpha$ AND DGK $\zeta$ AT THE PLASMA MEMBRANE}

Early studies found that in T cell lines, DGK $\alpha$ translocated from the cytosol to the plasma membrane in response to stimulation via an ectopically expressed muscarinic type 1 receptor as well as via the TCR (131). Examination of the redistribution of GFP-tagged DGK $\alpha$ revealed rapid but transient translocation of cytosolic DGK $\alpha$ to the plasma membrane after anti-CD3 and anti-CD28 crosslinking. Tyrosine-kinase phosphorylation, along with increases in intracellular calcium levels, was found to be essential for receptor-induced membrane translocation of DGK $\alpha$. Pre-treatment of cells with the type I DGK inhibitor R59949 enhanced DGK $\alpha$ translocation to the plasma membrane at $2 \mathrm{~min}$ but also prevented DGK $\alpha$ dissociation from the membrane even after $60 \mathrm{~min}$, suggesting that removal of DAG to produce PA may play a critical role in enzyme release. Results from this study thus showed that plasma membrane localization of DGK $\alpha$ is controlled not just by receptor-derived signals, but also by its own enzymatic activity.

More recent work has suggested that direct tyrosine phosphorylation of DGK $\alpha$ by the Src family kinase Lck may promote its membrane association in T cells (132). Results from the study showed that Lck phosphorylates DGK $\alpha$ at the $\mathrm{Y} 335$ residue in the hinge region between its $\mathrm{C} 1$ domains and the kinase domain. TCR triggering was found to induce rapid and transient phosphorylation of DGK $\alpha$ at Y335 in both Jurkat cells and primary human $\mathrm{T}$ cells. Fractionation analysis of Jurkat cells revealed that Y335phosphorylation was detected only in the membrane-associated (but not cytosolic) fraction. In addition, a Y335F mutant form of $\mathrm{DGK} \alpha$ failed to show plasma membrane localization in response to anti-CD3/anti-CD28 stimulation, in contrast to its WT counterpart. Immuno-precipitation experiments showed that Lck and $\mathrm{DGK} \alpha$ interacted with each other, but that the pool of DGK $\alpha$ pulled down with Lck was not phosphorylated at Y335. The authors hypothesize that Lck-mediated phosphorylation of DGK $\alpha$ may induce the latter's dissociation from Lck but play a role in stabilizing $\mathrm{DGK} \alpha$ at the membrane. Intriguingly, calcium flux induced by ionomycin was able to increase Y335-phosphorylation of DGK $\alpha$, leading the authors to hypothesize that binding of $\mathrm{Ca}^{++}$ to DGK $\alpha$ 's EF hands might induce a conformation change that increases Lck-mediated phosphorylation in the basal state.

Another study has since shown that c-Abl, a tyrosine-kinase involved in regulating cell cycle and proliferation, directly phosphorylates DGK $\alpha$ at Y218 in NIH 3T3 cells (133). Phosphorylation of this residue is thought to play an important role in seruminduced export of DGK $\alpha$ from the nucleus to the cytosol, as a Y218F mutant form was not exported from the nucleus in response to serum addition.

A role for SAP (an adaptor molecule recruited by the SLAM family of co-receptors) in inhibiting DGK $\alpha$ activity following TCR/CD28 stimulation has also been identified recently (134). Results from the study showed that DGK $\alpha$ (but not DGK $\zeta$ ) activity was reduced in response to TCR/CD28 or TCR/SLAM stimulation in Jurkat cells and human peripheral blood lymphocytes. However, such inhibition was not observed in Jurkat cells upon shRNAmediated knockdown of SAP. SAP knockdown was also found to impair the recruitment of DGK $\alpha$ to the plasma membrane selectively upon TCR/SLAM stimulation, but not TCR/CD28 stimulation, suggesting that the enzymatic activity and localization of DGK $\alpha$ may be regulated by distinct mechanisms. Overexpression of SAP was sufficient to reduce DGK $\alpha$ activity in Jurkat cells, providing further evidence of SAP's role as a negative regulator. Such a role for SAP is also corroborated by findings from previous studies that SAP-deficient T cells showed reduced recruitment of $\mathrm{PKC} \theta$ to the plasma membrane and diminished ERK1/2 activation upon TCR stimulation, leading to abnormal T cell differentiation and function (19). Pharmacological inhibition of DGK $\alpha$ activity by R59949 partially restored PKC $\theta$ membrane recruitment, ERK1/2 activation, and IL-2 production by SAP-deficient cells, suggesting that unrestrained DGK $\alpha$ activity might contribute to these signaling defects in the absence of SAP. 
Like its $\alpha$ counterpart, the $\zeta$ isoform of DGK also shows dynamic changes in its subcellular localization in response to signals via the TCR. Early studies showed that GFP-tagged DGK $\zeta$ rapidly translocated from the cytosol to the plasma membrane upon stimulation of an ectopically expressed muscarinic type 1 receptor, but not the TCR, in Jurkat T cells (135). Deletion of the C-terminal domain (containing the PDZ-binding domain and the ankyrin repeats), however, enabled DGK $\zeta$ to translocate to the plasma membrane following TCR stimulation, suggesting that these domains may negatively regulate membrane translocation. The results also revealed that intact cysteine-rich $\mathrm{Cl}$ domains and PKC $\theta$-mediated phosphorylation of the MARCKS domain are essential for DGK $\zeta$ membrane translocation, while enzymatic activity is dispensable. Others have shown that DGK $\zeta$ can translocate to the nucleus in COS-7 cells, and that this translocation is regulated by PKC-mediated phosphorylation of the MARCKS motif (136). Future studies should investigate a role for DGK $\zeta$ in regulating nuclear DAG levels in immune cells.

When a $\mathrm{T}$ cell recognizes cognate peptide-MHC complexes and co-stimulatory molecules on an antigen-presenting cell (APC), this leads to the formation of a specialized junction at the $\mathrm{T}$ cellAPC interface. This so-called "immunological synapse" typically consists of a central cluster of $T$ cell receptors surrounded by a ring of adhesion molecules, and synapse formation is thought to sustain robust signaling by facilitating the co-localization of kinases and adaptor proteins while excluding phosphatases $(137,138)$.

Previous studies have shown that DGK $\zeta$ can physically associate with RasGRP1 in co-transfection experiments, but a similar function for DGK $\alpha$ was not tested (139). A recent study directly analyzed the recruitment of DGK $\alpha$ and DGK $\zeta$ to the immunological synapse (140). Affinity purification of TCR complexes from Jurkat cells activated by anti-CD3 and anti-CD28 crosslinking suggested that both DGK isoforms were recruited rapidly to the TCR complex. However, video-microscopic experiments with GFP-tagged DGK proteins indicated that only DGK $\zeta$ translocates rapidly to the plasma membrane at the early stages of synapse formation. These discrepant results need to be interpreted with caution, as fusion with GFP could potentially alter a protein's structure and disrupt its normal localization pattern. However, RNA interference experiments from this study showed that PA production at the TCR complex was substantially reduced by knock down of DGK $\zeta$ but not DGK $\alpha$, strengthening the notion of functional differences between the isoforms. The addition of PMA was found to enhance DGK $\zeta$ activity upon TCR stimulation, indicating that DAG itself may regulate DGK $\zeta$ activity. The use of a fluorescently tagged DAG-sensor domain showed that both plasma membrane localization and kinase activity of DGK $\zeta$ were critical for DAG consumption at the immune synapse. Together, these results indicate a specific function for the DGK $\zeta$ isoform in regulating DAG levels at the immunological synapse. Further studies are required to fully characterize the TCR-induced translocation of DGK $\alpha$ and DGK $\zeta$ in primary $\mathrm{T}$ cells.

\section{DAG AND T CELL SECRETION}

The directed release of soluble factors is an important mechanism by which $\mathrm{T}$ cells kill target cells and communicate with other cell types. Early studies have shown that the microtubule-organizing center (MTOC) of a T cell reorients itself to a position just below the immunological synapse within minutes of TCR stimulation. Such polarization is though to aid in directional secretion by aligning the protein synthesis and secretion machinery of the $\mathrm{T}$ cell with the immune synapse $(141,142)$. Inhibiting MTOC translocation after TCR stimulation resulted in reduced phosphorylation of ZAP70 and LAT, disorganized immune synapse architecture and impaired IL-2 secretion, suggesting that MTOC translocation may also play a critical role in synapse formation and sustained TCR signaling (143).

More recent studies using a photoactivation system in which individual $\mathrm{T}$ helper cells can be activated by a pulse of ultraviolet light, have revealed a critical role for localized DAG production in MTOC polarization toward the synapse (144). MTOC polarization was abrogated in the presence of a PLC $\gamma 1$ inhibitor, but unaffected in the presence of a $\mathrm{Ca}^{2+}$ chelator, suggesting that DAG may play a critical role in the process. Treatment with PMA, but not ionomycin, disrupted MTOC polarization providing further evidence that DAG, not $\mathrm{Ca}^{2+}$, links PLC $\gamma 1$ activity to MTOC polarization. Data from imaging experiments showed robust accumulation of DAG-sensor proteins at the region of photoactivation, followed by reorientation of MTOC to this region with an average delay of 13 s between the two events. Treatment with a DGK inhibitor prevented sustained C1-GFP accumulation at the irradiated region and thereby impaired MTOC polarization. Experiments with a version of DAG that could be activated by ultraviolet light showed that a localized increase in DAG concentration was sufficient to drive transient polarization of the MTOC. Taken together, these experiments indicate an important role for DAG and DGKs in directional secretion. Treatment with PMA or a type II DGK inhibitor impaired T cell-mediated killing of target cells, without affecting degranulation. This suggests that localized DAG signaling plays a critical role in CTL killing not by blocking granule release but by directing the granules toward their appropriate target. Further studies using the photoactivation system have shown that DAG recruits three distinct PKC isoforms, $\varepsilon, \eta$, and $\theta$, to the immune synapse to promote cytoskeletal polarization following TCR stimulation (145).

A role for DGK $\alpha$ has also been established in the secretion of lethal FasL-bearing exosomes during activation induced cell death (AICD) (146). In this study, pre-treatment with a type I DGK $\alpha$ inhibitor increased the secretion of FasL-bearing exosomes upon TCR stimulation, and enhanced FasL-dependent AICD in J-HM12.2 cell line, suggesting that DGK may act as a negative regulator of exosome secretion. Based on the co-localization of DGK $\alpha$ with the trans-Golgi network and its presence in secreted exosomes, the authors proposed a model by which DAG may recruit PKD1 to the trans-Golgi network to promote vesicle budding.

Building on these results, a more recent study has identified a role for DGK $\alpha$ in the polarization of multi-vesicular bodies (MVBs) involved in the secretion of FasL-bearing exosomes (147). MVBs are late endosomes containing multiple exosomes/vesicles within their lumen that are formed by inward budding of the limiting membrane. In this study, inhibition of DGK $\alpha$ activity with a type I inhibitor was found to increase the number of mature MVBs, while overexpression of DGK $\alpha$ inhibited their formation, indicating that DGK $\alpha$ may negatively regulate the formation of 
MVBs. However, siRNA-mediated inhibition of DGK $\alpha$ impaired the polarization of MVBs and subsequent exosome release, suggesting a positive role for DGK $\alpha$ in this process. Thus, DGK $\alpha$ plays a complex role in the secretion of FasL-bearing exosomes, impairing their formation but aiding their polarization toward the immune synapse.

\section{DGK $\alpha$ AND DGK $\zeta$ IN CTL RESPONSES}

CD8 responses or CTL responses are critical for host defense against intracellular pathogens and tumors. CTL responses typically consist of three distinct phases - an expansion phase during which antigen-specific CD8 cells proliferate rapidly and differentiate into effector cells that kill infected target cells, a contraction phase during which 90-95 percent of these effector CD8 cells undergo apoptosis in response to diminishing antigen levels, and a memory maintenance phase in which the remaining 5-10 percent of cells are retained as a small but stable pool of fast-responding memory cells (148-150). Much effort over the recent years has focused on how signaling mechanisms in CD8 cells can be manipulated to alter the amplitude and kinetics of the CTL response. Preliminary experiments with lymphocytic choriomeningitis virus (LCMV) infection showed that mice deficient in DGK $\zeta$ mounted a more robust response to the pathogen than WT counterparts (121). DGK $\zeta$-deficient mice showed a greater increase of splenic CD8 cell numbers than WT mice at day 7, with a bigger portion of CD62 $\mathrm{L}^{\text {lo }} \mathrm{CD} 44^{\text {hi }}$ effector-memory $\left(\mathrm{T}_{\mathrm{EM}}\right)$ cells and IFN $\gamma$-producing cells within the CD8 population. Viral titers were 50-70 percent lower in DGK $\zeta$-deficient mice than WT mice, arguing that DGK $\zeta$ activity may negatively regulate CTL responses.

These results were confirmed and extended by a subsequent study, which showed that DGK activity differentially regulates primary and memory responses to LCMV (151). In this study, both DGK $\alpha$ KO and DGK $\zeta$ KO mice showed enhanced expansion and increased cytokine production upon LCMV infection, but contained fewer memory cells than WT counterparts after a 4-month period. When equal numbers of memory cells from these mice were transferred to new recipients and re-challenged with LCMV, DGK-deficient memory cells expanded significantly less than WT memory cells, indicating that DGK activity may somehow promote the expansion of memory cells. Other studies have revealed that the temporal kinetics of mTORc1 activity may play a critical role in effector versus memory differentiation of CD8 cells (152, 153). Results from these studies suggest that sustained mTORc1 activity may induce the expression of the T-box transcription factor T-bet that promotes effector differentiation. The identification of DGKs as negative regulators of mTOR activity (113) suggests the possibility that sustained mTORcl activity in DGK-deficient CD8 cells might favor effector differentiation and mitigate memory formation. While mTORc1 activity was indeed found to be elevated in DGK-deficient CD8 cells (as measured by phosphorylation of the ribosomal protein S6) (151), further studies are required to dissect the contribution of enhanced mTORcl activity to the dysregulation of CD8 responses seen in DGK $\alpha \mathrm{KO}$ and DGK $\zeta$ KO mice.

DGK $\zeta$ also acts as a negative regulator of anti-tumor CTL responses in an EL4-Ova lymphoma model (154). In this model, significantly smaller tumors were recovered from DGK $\zeta$-deficient

mice as compared to WT mice, 3 weeks after implantation of tumor cells. Evaluation of CD8 splenocytes revealed a higher proportion of $\mathrm{T}_{\mathrm{EM}}$ cells and a higher proportion of Ova-specific CD8 cells in DGK $\zeta$-deficient mice than in WT mice. An increased percentage of tumor-infiltrating CD8 cells was also found to be proliferating in DGK $\zeta$-deficient mice as compared to WT counterparts. Taken together, these results suggest that DGK $\zeta$ activity may play a critical role in restraining anti-tumor responses, closely mirroring its functions during CTL responses to viral infection. When naïve WT-OT1 and DGK $\zeta$ KO-OT1 cells were adoptively transferred into congenically marked recipients that subsequently received EL4-Ova lymphoma cells, recipients with DGKלKO-OT1 cells developed smaller tumors. DGK $\zeta$ KO-OT1 cells also contained a bigger pool of CD $44^{\text {hi }}$ cells and IL-2 producing cells. Collectively, these results argue for a CD8 cell-intrinsic role for DGK $\zeta$ in curtailing anti-tumor responses.

Investigation of tumor-infiltrating CD8 cells in human renal cell carcinoma patients showed increased DGK $\alpha$ activity and diminished signaling via MAPK pathways, as compared to CD8 cells that were present in non-tumor areas of the kidney (155). Increased DGK $\alpha$ activity was associated with defects in granule exocytosis and lytic function of these CD8 cells, and treatment with a DGK $\alpha$ inhibitor was able to increase ERK phosphorylation.

Table 1 | Biological functions of DGKs in T cells and other immune cells.

\section{Functions regulated by DGK activity}

DAG metabolism at the T cell-APC

immunological synapse

Development of $i$ NKT cells

T cell activation and anergy

CD8 T cell responses to pathogens and tumors

MTOC polarization and directional secretion

Mast cell degranulation and cytokine production

Macrophage and DC cytokine production

\section{Reference}

Sanjuan et al. (131)

Topham and Prescott (139)

Santos et al. (135)

Merino et al. (132)

Baldanzi et al. (134)

Gharbi et al. (140)

Matsubara et al. (133)

Guo et al. (112)

Gorentla et al. (113)

Shen et al. (120)

Zhong et al. (6)

Zhong et al. (121)

Olenchock et al. (158)

Zha et al. (130)

Zhong et al. (121)

Riese et al. (154)

Prinz et al. (155)

Shin et al. (151)

Alonso et al. (146)

Quann et al. (144)

Alonso et al. (147)

Olenchock et al. (158)

Liu et al. (159) 
Culturing with low-dose IL-2 reduced DGK $\alpha$ expression and enhanced ERK activation and degranulation. IL-2 treatment also increased the frequency of tumor-infiltrating cells that produced perforin, granzyme $\mathrm{B}$, or IFN $\gamma$. Taken together, these data indicate that increased DGK activity and DAG metabolism dampen the responsiveness of tumor-infiltrating CTLs in a reversible manner. What factors in the tumor microenvironment drive increased DGK activity in CD8 cells is an important question that remains to be addressed.

\section{ROLE OF DGK ACTIVITY IN OTHER IMMUNE CELLS}

Apart from T cells, DAG and PA are critical signaling intermediates in several cell types including mast cells, dendritic cells (DCs), and macrophages. It is therefore not surprising that tight regulation of DAG and PA levels by DGK activity is essential for normal functioning of these cell types. Mast cells are abundant at the host's interface with the environment, such as the skin and mucose (156). While best known for their role in the pathogenesis of asthma, allergy, and anaphylaxis, mast cells also play a critical role in pathogen surveillance and defense against parasites (157). In contrast to observations with T cells, mast cell function in vivo was diminished in the absence of the DGK $\zeta$, impairment of local anaphylactic responses (158). Bone marrow-derived mast cells that lacked DGK $\zeta$ showed impaired degranulation but enhanced production of cytokines such as IL-6 when stimulated ex vivo. Other studies have shown that both the $\zeta 1$ and $\zeta 2$ isoforms of DGK $\zeta$ expressed in bone marrow-derived macrophages and DCs, with $\zeta 1$ being predominant (159). Considered "professional phagocytes," macrophages, and DCs express a diverse array of pattern recognition receptors (including toll-like receptors or TLRs) that enable them to detect the presence of pathogens and cell debris. Upon stimulation with Toxoplasma gondii-stable tachyzoite antigen (STAg, which activates multiple TLRs), DGK $\zeta$ deficient splenic DCs and bone marrow-derived macrophages (BMM $\phi)$ produced less TNF $\alpha$ and IL-12 p40 than WT counterparts. Consistent with this impairment in cytokine production, both resistance to endotoxin shock and susceptibility to $T$. gondii infection were increased in $\mathrm{DGK} \zeta \mathrm{KO}$ mice. While these findings

\section{REFERENCES}

1. Eyster KM. The membrane and lipids as integral participants in signal transduction: lipid signal transduction for the non-lipid biochemist. $A d v$ Physiol Educ (2007) 31:5-16. doi:10.1152/advan.00088.2006

2. Fernandis AZ, Wenk MR. Membrane lipids as signaling molecules. Curr Opin Lipidol (2007) 18:121-8. doi:10. 1097/MOL.0b013e328082e4d5

3. Merida I, Avila-Flores A, Merino E. Diacylglycerol kinases: at the hub of cell signalling. Biochem J (2008) 409:1-18. doi:10.1042/BJ20071040

4. Cai J, Abramovici H, Gee SH, Topham MK. Diacylglycerol kinases as sources of phosphatidic acid. Biochim Biophys Acta (2009) 1791:942-8. doi:10.1016/j.bbalip.2009.02.010

5. Sakane F, Imai $S$, Kai $M$, Yasuda S, Kanoh H. Diacylglycerol kinases: why so many of them? Biochim Biophys Acta (2007) 1771:793-806. doi:10.1016/j.bbalip.2007.04.006

6. Zhong XP, Hainey EA, Olenchock BA, Zhao H, Topham MK, Koretzky GA. Regulation of $\mathrm{T}$ cell receptor-induced activation of the Ras-ERK pathway by diacylglycerol kinase zeta. $J$ Biol Chem (2002) 277:31089-98. doi:10.1074/jbc.M203818200

7. Zhong XP, Guo R, Zhou H, Liu C, Wan CK. Diacylglycerol kinases in immune cell function and selftolerance. Immunol Rev (2008)

provide tantalizing evidence of a role for DGK $\zeta$ in regulating innate immune responses, further studies are required to gain a better understanding of the underlying molecular mechanisms. In addition, the involvement of other DGK isoforms in the regulation of innate immune responses remains to be investigated. The varied biological functions of DGK activity in T cells and other immune cells are summarized in Table 1.

\section{SUMMARY}

Over the past few years, a remarkable number of elegant studies that have furthered our understanding of the roles of DAGmediated and PA-mediated signaling pathways, and their regulation by enzymes of the DGK family, in T cell development and function. A role for DGK activity has been identified in a variety of critical processes including conventional $\alpha \beta$ T cell and $i$ NKT cell development, $\mathrm{T}$ cell activation and anergy, directional secretion, and suppression of CD8 responses against viruses and tumors. While a multitude of interesting and fundamental questions in the field have been addressed by these recent studies, it is important to note that perhaps just as many others await answers. The roles of DGK-derived PA and PLD-derived PA in T cell development and function have proved challenging to dissect, as have differences between DGK isoforms in terms of substrate specificity and subcellular localization. Key elements such as transcription factors, microRNAs, and post-translational modifications that control the dynamic expression and function of DGKs during a T cell's lifetime also remain relatively unexplored. Applying the scientific method to answer these intriguing questions is likely to yield a better understanding of how DAG and PA signals and DGK activity regulate immune responses, enhancing our ability to modulate such responses to quell self-reactivity or generate protective immunity.

\section{ACKNOWLEDGMENTS}

This work is supported by the National Institutes of Health (AI076357, AI079088, and AI101206) and the American Cancer Society (RSG-08-186-01-LIB). The authors declare no conflict of interest.

224:249-64. doi:10.1111/j.1600065X.2008.00647.x

8. Breitkreutz D, BraimanWiksman L, Daum N, Denning MF, Tennenbaum T. Protein kinase $\mathrm{C}$ family: on the crossroads of cell signaling in skin and tumor epithelium. J Cancer Res Clin Oncol (2007) 133:793808. doi:10.1007/s00432-0070280-3

9. Gould CM, Newton AC. The life and death of protein kinase C. Curr Drug Targets (2008) 9:61425. doi:10.2174/13894500878513 2411

10. Huang J, Lo PF, Zal T, Gascoigne NR, Smith BA, Levin SD, et al. CD28 plays a critical role in the segregation of PKC theta within the immunologic synapse. Proc Natl Acad Sci U S A (2002) 99:9369-73. doi:10.1073/pnas.142298399

11. Yokosuka T, Kobayashi W, Sakata-Sogawa K, Takamatsu M, Hashimoto-Tane A, Dustin ML, et al. Spatiotemporal regulation of $\mathrm{T}$ cell costimulation by TCRCD28 microclusters and protein kinase $\mathrm{C}$ theta translocation. Immunity (2008) 29:589-601. doi:10.1016/j.immuni.2008. 08.011

12. Sun Z, Arendt CW, Ellmeier W, Schaeffer EM, Sunshine MJ, Gandhi L, et al. PKC-theta is required for TCR-induced NFkappaB activation in mature but not immature T lymphocytes. Nature (2000) 404:402-7. doi:10.1038/35006090 
13. Isakov $\mathrm{N}$, Altman A. Protein kinase $\mathrm{C}$ (theta) in $\mathrm{T}$ cell activation. Annu Rev Immunol (2002) 20:761-94. doi:10.1146/annu rev.immunol.20.100301.064807

14. Hayashi K, Altman A. Protein kinase $\mathrm{C}$ theta (PKCtheta): a key player in $\mathrm{T}$ cell life and death. Pharmacol Res (2007) 55:537-44. doi:10.1016/j.phrs.2007.04.009

15. Schmidt-Supprian M, Tian J, Grant EP, Pasparakis M, Maehr R, Ovaa $\mathrm{H}$, et al. Differential dependence of CD4+CD25+ regulatory and natural killer-like T cells on signals leading to NF-kappaB activation. Proc Natl Acad Sci U S A (2004) 101:4566-71. doi:10.1073/pnas.0400885101

16. Fang $X$, Wang $R$, Ma J, Ding Y, Shang W, Sun Z. Ameliorated ConA-induced hepatitis in the absence of PKC-theta. PLoS ONE (2012) 7:e31174. doi: 10.1371/journal.pone.0031174

17. Manicassamy S, Gupta S, Huang Z, Sun Z. Protein kinase Ctheta-mediated signals enhance CD4+ $\mathrm{T}$ cell survival by upregulating $\mathrm{Bcl}-\mathrm{xL}$. J Immunol (2006) 176:6709-16.

18. Werlen G, Jacinto E, Xia Y, Karin M. Calcineurin preferentially synergizes with PKCtheta to activate JNK and IL2 promoter in $\mathrm{T}$ lymphocytes. EMBO J (1998) 17:3101-11. doi:10.1093/emboj/17.11.3101

19. Cannons JL, Yu LJ, Hill B, Mijares LA, Dombroski D, Nichols KE, et al. SAP regulates $\mathrm{T}(\mathrm{H}) 2$ differentiation and PKC-theta-mediated activation of NF-kappaB1. Immunity (2004) 21:693-706. doi: 10.1016/j.immuni.2004.09.012

20. Marsland BJ, Soos TJ, Spath G, Littman DR, Kopf M. Protein kinase $\mathrm{C}$ theta is critical for the development of in vivo $\mathrm{T}$ helper ( $\mathrm{Th}) 2$ cell but not Th1 cell responses. J Exp Med (2004) 200:181-9. doi:10.1084/jem.20032229

21. Kwon MJ, Ma J, Ding Y, Wang R, Sun Z. Protein kinase Ctheta promotes Th17 differentiation via upregulation of Stat3. J Immunol (2012) 188:5887-97. doi:10.4049/jimmunol.1102941

22. Carrasco S, Merida I. Diacylglycerol-dependent binding recruits PKCtheta and RasGRP1 Cl domains to specific subcellular localizations in living $\mathrm{T}$ lymphocytes. $\mathrm{Mol}$ Biol Cell (2004) 15:2932-42. doi:10.1091/mbc.E03-11-0844
23. Roose JP, Mollenauer M, Gupta VA, Stone J, Weiss A. A diacylglycerol-protein kinase C-RasGRP1 pathway directs Ras activation upon antigen receptor stimulation of $\mathrm{T}$ cells. Mol Cell Biol (2005) 25:4426-41. doi:10.1128/MCB.25.11.44264441.2005

24. Ebinu JO, Stang SL, Teixeira C, Bottorff DA, Hooton J, Blumberg PM, et al. RasGRP links T-cell receptor signaling to Ras. Blood (2000) 95:3199-203.

25. Dower NA, Stang SL, Bottorff DA, Ebinu JO, Dickie P, Ostergaard HL, et al. RasGRP is essential for mouse thymocyte differentiation and TCR signaling. Nat Immunol (2000) 1:317-21. doi:10.1038/80799

26. Priatel JJ, Teh SJ, Dower NA, Stone JC, Teh HS. RasGRP1 transduces low-grade TCR signals which are critical for $\mathrm{T}$ cell development, homeostasis, and differentiation. Immunity (2002) 17:617-27. doi:10.1016/S10747613(02)00451-X

27. Chen Y, Ci X, Gorentla B, Sullivan SA, Stone JC, Zhang W, et al. Differential requirement of RasGRP1 for gammadelta $\mathrm{T}$ cell development and activation. J Immunol (2012) 189:61-71. doi:10.4049/jimmunol.1103272

28. Priatel JJ, Chen $\mathrm{X}$, Huang YH, Chow MT, Zenewicz LA, Coughlin JJ, et al. RasGRP1 regulates antigen-induced developmental programming by naive CD8 T cells. J Immunol (2010) 184:666-76. doi:10.4049/jimmunol.0803521

29. Wang QJ. PKD at the crossroads of DAG and PKC signaling. Trends Pharmacol Sci (2006) 27:317-23. doi:10.1016/j.tips.2006.04.003

30. Rozengurt E, Rey O, Waldron RT. Protein kinase D signaling. J Biol Chem (2005) 280:13205-8. doi:10.1074/jbc.R500002200

31. Marklund U, Lightfoot $\mathrm{K}$, Cantrell D. Intracellular location and cell contextdependent function of protein kinase D. Immunity (2003) 19:491-501. doi:10.1016/S10747613(03)00260-7

32. Mullin MJ, Lightfoot K, Marklund U, Cantrell DA. Differential requirement for RhoA GTPase depending on the cellular localization of protein kinase D. J Biol Chem (2006) 281:2508996. doi:10.1074/jbc.M60359 1200
33. Brose N, Rosenmund C. Move over protein kinase $\mathrm{C}$, you've got company: alternative cellular effectors of diacylglycerol and phorbol esters. $J$ Cell Sci (2002) 115:4399-411. doi:10.1242/jcs.00122

34. Koch H, Hofmann K, Brose N. Definition of Munc13homology-domains and characterization of a novel ubiquitously expressed Munc13 isoform. Biochem J (2000) 349:247-53. doi:10.1042/0264-6021:3490247

35. Shirakawa R, Higashi T, Tabuchi A, Yoshioka A, Nishioka $\mathrm{H}$, Fukuda M, et al. Munc13-4 is a GTP-Rab27-binding protein regulating dense core granule secretion in platelets. $J$ Biol Chem (2004) 279:10730-7. doi:10.1074/jbc.M309426200

36. Feldmann J, Callebaut I, Raposo G, Certain S, Bacq D, Dumont C, et al. Munc13-4 is essential for cytolytic granules fusion and is mutated in a form of familial hemophagocytic lymphohistiocytosis (FHL3). Cell (2003) 115:461-73. doi:10.1016/S00928674(03)00855-9

37. Menager MM, Menasche G Romao M, Knapnougel P, Ho $\mathrm{CH}$, Garfa $\mathrm{M}$, et al. Secretory cytotoxic granule maturation and exocytosis require the effector protein hMunc13-4. Nat Immunol (2007) 8:257-67. doi:10.1038/ni1431

38. Johnson JL, Hong H, Monfregola J, Kiosses WB, Catz SD. Munc13-4 restricts motility of Rab27a-expressing vesicles to facilitate lipopolysaccharideinduced priming of exocytosis in neutrophils. $J$ Biol Chem (2011) 286:5647-56. doi:10.1074/jbc.M110.184762

39. Monfregola J, Johnson JL, Meijler MM, Napolitano G, Catz SD. MUNC13-4 protein regulates the oxidative response and is essential for phagosomal maturation and bacterial killing in neutrophils. J Biol Chem (2012) 287:44603-18. doi:10.1074/jbc.M112.414029

40. Song Y, Ailenberg M, Silverman M. Human munc13 is a diacylglycerol receptor that induces apoptosis and may contribute to renal cell injury in hyperglycemia. Mol Biol Cell (1999) 10:1609-19.

41. Caloca MJ, Garcia-Bermejo ML, Blumberg PM, Lewin NE, Kremmer E, Mischak H, et al. Beta2chimaerin is a novel target for diacylglycerol: binding properties and changes in subcellular localization mediated by ligand binding to its $\mathrm{Cl}$ domain. Proc Natl Acad Sci U S A (1999) 96:11854-9. doi:10.1073/pnas.96.21.11854

42. Yang C, Kazanietz MG. Chimaerins: GAPs that bridge diacylglycerol signalling and the small G-protein Rac. Biochem J (2007) 403:1-12. doi:10.1042/BJ20061750

43. Caloca MJ, Delgado P, Alarcon B, Bustelo XR. Role of chimaerins, a group of Racspecific GTPase activating proteins, in T-cell receptor signaling. Cell Signal (2008) 20:758-70. doi:10.1016/j.cellsig.2007.12.015

44. Siliceo M, Garcia-Bernal D, Carrasco S, Diaz-Flores E, Coluccio Leskow F, Teixido J, et al. Beta2-chimaerin provides a diacylglycerol-dependent mechanism for regulation of adhesion and chemotaxis of $\mathrm{T}$ cells. J Cell Sci (2006) 119:141-52. doi:10.1242/jcs.02722

45. Jenkins GM, Frohman MA. Phospholipase D: a lipid centric review. Cell $\mathrm{Mol}$ Life Sci (2005) 62:2305-16. doi:10.1007/s00018-005-5195-z

46. Csaki LS, Reue K. Lipins: multifunctional lipid metabolism proteins. Annu Rev Nutr (2010) 30:257-72. doi:10.1146/ annurev.nutr.012809.104729

47. Wang $\mathrm{X}$, Devaiah SP, Zhang W, Welti R. Signaling functions of phosphatidic acid. Prog Lipid Res (2006) 45:250-78. doi:10.1016/j.plipres.2006.01.005

48. Foster DA. Regulation of mTOR by phosphatidic acid? Cancer Res (2007) 67:1-4. doi:10.1158/0008-5472.CAN06-3016

49. Fang $\mathrm{Y}$, Vilella-Bach $\mathrm{M}$, Bachmann R, Flanigan A Chen J. Phosphatidic acidmediated mitogenic activation of mTOR signaling. Science (2001) 294:1942-5. doi:10.1126/science.1066015

50. Chen J, Fang Y. A novel pathway regulating the mammalian target of rapamycin (mTOR) signaling. Biochem Pharmacol (2002) 64:1071-7. doi:10.1016/S00062952(02)01263-7

51. Yoon MS, Sun Y, Arauz E, Jiang Y, Chen J. Phosphatidic acid activates mammalian target of rapamycin complex 1 (mTORC1) kinase by displacing FK506 binding 
protein 38 (FKBP38) and exerting an allosteric effect. $J$ Biol Chem (2011) 286:29568-74. doi:10.1074/jbc.M111.262816

52. Winter JN, Fox TE, Kester M, Jefferson LS, Kimball SR. Phosphatidic acid mediates activation of mTORCl through the ERK signaling pathway. Am J Physiol Cell Physiol (2010) 299:C335-44. doi:10.1152/ajpcell.00039.2010

53. Toschi A, Lee E, Xu L, Garcia A, Gadir N, Foster DA. Regulation of mTORC1 and mTORC2 complex assembly by phosphatidic acid: competition with rapamycin. Mol Cell Biol (2009) 29:1411-20. doi:10.1128/MCB.00782-08

54. Avila-Flores A, Santos T, Rincon E, Merida I. Modulation of the mammalian target of rapamycin pathway by diacylglycerol kinaseproduced phosphatidic acid. $J$ Biol Chem (2005) 280:10091-9. doi:10.1074/jbc.M412296200

55. Lim HK, Choi YA, Park W, Lee T, Ryu SH, Kim SY, et al. Phosphatidic acid regulates systemic inflammatory responses by modulating the Akt-mammalian target of rapamycin-p70 S6 kinase 1 pathway. $J$ Biol Chem (2003) 278:45117-27. doi:10.1074/jbc.M303789200

56. Andresen BT, Rizzo MA, Shome $\mathrm{K}$, Romero G. The role of phosphatidic acid in the regulation of the Ras/MEK/Erk signaling cascade. FEBS Lett (2002) 531:65-8. doi:10.1016/S00145793(02)03483-X

57. Ghosh S, Strum JC, Sciorra VA, Daniel L, Bell RM. Raf-1 kinase possesses distinct binding domains for phosphatidylserine and phosphatidic acid. Phosphatidic acid regulates the translocation of Raf- 1 in 12-O-tetradecanoylphorbol-13acetate-stimulated Madin-Darby canine kidney cells. J Biol Chem (1996) 271:8472-80. doi:10.1074/jbc.271.14.8472

58. Rizzo MA, Shome K, Vasudevan C, Stolz DB, Sung TC, Frohman MA, et al. Phospholipase $\mathrm{D}$ and its product, phosphatidic acid, mediate agonistdependent raf-1 translocation to the plasma membrane and the activation of the mitogenactivated protein kinase pathway. J Biol Chem (1999) 274:1131-9. doi:10.1074/jbc.274.2.1131

59. Shome K, Vasudevan C, Romero G. ARF proteins mediate insulin-dependent activation of phospholipase D. Curr Biol (1997) 7:387-96. doi:10.1016/S09609822(06)00186-2

60. Rizzo MA, Shome K, Watkins SC, Romero G. The recruitment of Raf- 1 to membranes is mediated by direct interaction with phosphatidic acid and is independent of association with Ras. J Biol Chem (2000) 275:23911-8. doi:10.1074/jbc.M001553200

61. Morrison DK. KSR: a MAPK scaffold of the Ras pathway? JCell Sci (2001) 114:1609-12.

62. Kraft CA, Garrido JL, Fluharty E, Leiva-Vega L, Romero G. Role of phosphatidic acid in the coupling of the ERK cascade. $J$ Biol Chem (2008) 283:36636-45. doi:10.1074/jbc.M804633200

63. Zhao C, Du G, Skowronek K, Frohman MA, Bar-Sagi D. Phospholipase D2-generated phosphatidic acid couples EGFR stimulation to Ras activation by Sos. Nat Cell Biol (2007) 9:706-12. doi:10.1038/ncb1594

64. Mor A, Campi G, Du G, Zheng Y, Foster DA, Dustin ML, et al. The lymphocyte functionassociated antigen-1 receptor costimulates plasma membrane Ras via phospholipase D2. Nat Cell Biol (2007) 9:713-9. doi:10.1038/ncb1592

65. Norambuena A, Metz C, Vicuna L, Silva A, Pardo E, Oyanadel C, et al. Galectin-8 induces apoptosis in Jurkat $\mathrm{T}$ cells by phosphatidic acid-mediated ERK1/2 activation supported by protein kinase A down-regulation. $J$ Biol Chem (2009) 284:12670-9. doi:10.1074/jbc.M808949200

66. Tribulatti MV, Cattaneo V, Hellman U, Mucci J, Campetella O. Galectin-8 provides costimulatory and proliferative signals to $\mathrm{T}$ lymphocytes. $J$ Leukoc Biol (2009) 86:371-80. doi:10.1189/jlb.0908529

67. Cockcroft S. Phosphatidic acid regulation of phosphatidylinositol 4-phosphate 5-kinases. Biochim Biophys Acta (2009) 1791:905-12. doi:10.1016/j.bbalip.2009.03.007

68. Moritz A, de Graan PN, Gispen WH, Wirtz KW. Phosphatidic acid is a specific activator of phosphatidylinositol-4phosphate kinase. J Biol Chem (1992) 267:7207-10.

69. Jenkins GH, Fisette PL, Anderson RA. Type I phosphatidylinositol 4-phosphate 5-kinase isoforms are specifically stimulated by phosphatidic acid. J Biol Chem (1994) 269:11547-54.

70. Jarquin-Pardo M, Fitzpatrick A, Galiano FJ, First EA, Davis JN. Phosphatidic acid regulates the affinity of the murine phosphatidylinositol 4-phosphate 5-kinase-Ibeta for phosphatidylinositol4-phosphate. J Cell Biochem (2007) 100:112-28. doi:10.1002/jcb.21027

71. Luo B, Prescott SM, Topham MK. Diacylglycerol kinase zeta regulates phosphatidylinositol 4-phosphate 5-kinase Ialpha by a novel mechanism. Cell Signal (2004) 16:891-7. doi:10.1016/j.cellsig.2004.01.010

72. Galandrini R, Micucci F, Tassi I, Cifone MG, Cinque B, Piccoli M, et al. Arf6: a new player in FcgammaRIIIA lymphocyte-mediated cytotoxicity. Blood (2005) 106:577-83. doi:10.1182/blood2004-10-4100

73. Micucci F, Capuano C, Marchetti E, Piccoli M, Frati L, Santoni $\mathrm{A}$, et al. PI5KI-dependent signals are critical regulators of the cytolytic secretory pathway. Blood (2008) 111:416572. doi:10.1182/blood-2007-08108886

74. Cohen PT. Protein phosphatase $1-$ targeted in many directions. $J$ Cell Sci (2002) 115:241-56.

75. Jones JA, Hannun YA. Tight binding inhibition of protein phosphatase-1 by phosphatidic acid. Specificity of inhibition by the phospholipid. $J$ Biol Chem (2002) 277:15530-8. doi:10.1074/jbc.M111555200

76. Jones JA, Rawles R, Hannun YA. Identification of a novel phosphatidic acid binding domain in protein phosphatase-1. Biochemistry (2005) 44:13235-45. doi:10.1021/bi0505159

77. Li X, Schwacha MG, Chaudry IH, Choudhry MA. A role of PP1/PP2A in mesenteric lymph node $\mathrm{T}$ cell suppression in a two-hit rodent model of alcohol intoxication and injury. $J$ Leukoc Biol (2006) 79:453-62. doi:10.1189/jlb.0705369

78. Lorenz U. SHP-1 and SHP-2 in $\mathrm{T}$ cells: two phosphatases functioning at many levels. Immunol Rev (2009) 228:342-59. doi:10.1111/j.1600065X.2008.00760. $\mathrm{x}$

79. Shultz LD, Schweitzer PA, Rajan $\mathrm{TV}$, Yi T, Ihle JN, Matthews RJ, et al. Mutations at the murine motheaten locus are within the hematopoietic cell protein-tyrosine phosphatase (Hcph) gene. Cell (1993) 73:1445-54. doi:10.1016/00928674(93)90369-2

80. Zhang J, Somani AK, Yuen D, Yang Y, Love PE, Siminovitch KA. Involvement of the SHP-1 tyrosine phosphatase in regulation of $\mathrm{T}$ cell selection. J Immunol (1999) 163:3012-21.

81. Fowler CC, Pao LI, Blattman JN, Greenberg PD. SHP-1 in $\mathrm{T}$ cells limits the production of CD8 effector cells without impacting the formation of long-lived central memory cells. J Immunol (2010) 185:325667. doi:10.4049/jimmunol.100 1362

82. Tomic S, Greiser U, Lammers R, Kharitonenkov A, Imyanitov E, Ullrich A, et al. Association of $\mathrm{SH} 2$ domain protein tyrosine phosphatases with the epidermal growth factor receptor in human tumor cells. Phosphatidic acid activates receptor dephosphorylation by PTP1C. $J$ Biol Chem (1995) 270:21277-84. doi:10.1074/jbc.270.36.21277

83. Frank C, Keilhack H, Opitz F, Zschornig O, Bohmer FD. Binding of phosphatidic acid to the protein-tyrosine phosphatase SHP-1 as a basis for activity modulation. Biochemistry (1999) 38:11993-2002. doi:10.1021/bi982586w

84. Takahama Y. Journey through the thymus: stromal guides for T-cell development and selection. Nat Rev Immunol (2006) 6:127-35. doi:10.1038/nri1781

85. Weerkamp F, Pike-Overzet $\mathrm{K}$, Staal FJ. T-sing progenitors to commit. Trends Immunol (2006) 27:125-31. doi:10.1016/j.it.2006.01.006

86. Ellmeier W, Sawada S, Littman DR. The regulation of $\mathrm{CD} 4$ and CD8 coreceptor gene expression during T cell development. Annu Rev Immunol (1999) 17:523-54. doi:10.1146/annurev.immunol. 17.1.523

87. Taniuchi I, Ellmeier W. Transcriptional and epigenetic regulation of $\mathrm{CD} 4 / \mathrm{CD} 8$ lineage choice. Adv Immunol (2011) 110:71-110. doi:10.1016/B9780-12-387663-8.00003-X

88. Misslitz A, Bernhardt G, Forster R. Trafficking on serpentines: molecular insight on how maturating $\mathrm{T}$ cells find their winding paths in the thymus. Immunol Rev (2006) 
209:115-28. doi:10.1111/j.01052896.2006.00351.x

89. Bunting MD, Comerford I, McColl SR. Finding their niche: chemokines directing cell migration in the thymus. Immunol Cell Biol (2011) 89:185-96. doi:10.1038/icb.2010.142

90. Jameson SC, Hogquist KA, Bevan MJ. Positive selection of thymocytes. Annu Rev Immunol (1995) 13:93-126. doi:10.1146/ annurev.iy.13.040195.000521

91. Dervovic D, Zuniga-Pflucker JC. Positive selection of $\mathrm{T}$ cells, an in vitro view. Semin Immunol (2010) 22:276-86. doi:10.1016/j.smim.2010.04.014

92. Sprent J, Kishimoto $H$. The thymus and negative selection. Immunol Rev (2002) 185:126-35. doi:10.1034/j.1600065X.2002.18512.X

93. Von Boehmer H, Melchers F. Checkpoints in lymphocyte development and autoimmune disease. Nat Immunol (2010) 11:14-20. doi:10.1038/ni.1794

94. Starr TK, Jameson SC, Hogquist KA. Positive and negative selection of T cells. Annu Rev Immunol (2003) 21:139-76. doi:10.1146/annurev.immunol. 21.120601.141107

95. Wiegers GJ, Kaufmann M, Tischner D, Villunger A. Shaping the T-cell repertoire: a matter of life and death. Immunol Cell Biol (2011) 89:33-9. doi:10.1038/icb.2010.127

96. Matloubian M, Lo CG, Cinamon G, Lesneski MJ, Xu Y, Brinkmann V, et al. Lymphocyte egress from thymus and peripheral lymphoid organs is dependent on S1P receptor 1. Nature (2004) 427:355-60. doi:10.1038/nature02284

97. Cyster JG, Schwab SR. Sphingosine-1-phosphate and lymphocyte egress from lymphoid organs. Annu Rev Immunol (2012) 30:69-94. doi:10.1146/annurev-immunol020711-075011

98. Michie AM, Trop S, Wiest DL, Zuniga-Pflucker JC. Extracellular signal-regulated kinase (ERK) activation by the pre-T cell receptor in developing thymocytes in vivo. $J$ Exp Med (1999) 190:1647-56. doi:10.1084/jem.190.11.1647

99. Golec DP, Dower NA, Stone JC, Baldwin TA. RasGRP1, but not RasGRP3, is required for efficient thymic betaselection and ERK activation downstream of CXCR4. PLoS ONE (2013) 8:e53300. doi:10. 1371/journal.pone.0053300

100. Fu G, Chen Y, Yu M, Podd A, Schuman J, He Y, et al. Phospholipase $\mathrm{C}\{$ gamma 1 is essential for $\mathrm{T}$ cell development, activation, and tolerance. J Exp Med (2010) 207:309-18. doi:10.1084/jem.20090880

101. Swan KA, Alberola-Ila J, Gross JA, Appleby MW, Forbush KA, Thomas JF, et al. Involvement of p21ras distinguishes positive and negative selection in thymocytes. EMBO J (1995) 14:276-85.

102. Alberola-Ila J, Forbush KA, Seger R, Krebs EG, Perlmutter RM. Selective requirement for MAP kinase activation in thymocyte differentiation. Nature (1995) 373:620-3. doi:10.1038/373620a0

103. Pages G, Guerin S, Grall D, Bonino F, Smith A, Anjuere F, et al. Defective thymocyte maturation in p44 MAP kinase (Erk 1) knockout mice. Science (1999) 286:1374-7. doi: 10.1126/science.286.5443.1374

104. Fischer AM, Katayama CD, Pages G, Pouyssegur J, Hedrick SM. The role of erk1 and erk2 in multiple stages of $\mathrm{T}$ cell development. Immunity (2005) 23:431-43. doi: 10.1016/j.immuni.2005.08.013

105. Mahalingam M, Cooper JA. Phosphorylation of mammalian eIF4E by Mnk1 and Mnk2: tantalizing prospects for a role in translation. Prog Mol Subcell Biol (2001) 27:132-42. doi:10. 1007/978-3-662-09889-9_5

106. Buxade M, Parra-Palau JL, Proud CG. The Mnks: MAP kinaseinteracting kinases (MAP kinase signal-integrating kinases). Front Biosci (2008) 13:5359-73. doi: $10.2741 / 3086$

107. Gorentla BK, Krishna S, Shin $\mathrm{J}$, Inoue $\mathrm{M}$, Shinohara ML, Grayson JM, et al. Mnk1 and 2 are dispensable for $\mathrm{T}$ cell development and activation but important for the pathogenesis of experimental autoimmune encephalomyelitis. J Immunol (2013) 190:1026-37. doi:10.4049/jimmunol.1200026

108. Morley SC, Weber KS, Kao H, Allen PM. Protein kinase C-theta is required for efficient positive selection. J Immunol (2008) 181:4696-708.

109. Gruber T, Pfeifhofer-Obermair $\mathrm{C}$, Baier G. PKCtheta is necessary for efficient activation of NFkappaB, NFAT, and AP-1 during positive selection of thymocytes. Immunol Lett (2010) 132:6-11. doi:10.1016/j.imlet.2010.04.008

110. Schmidt-Supprian M, Courtois G, Tian J, Coyle AJ, Israel A, Rajewsky K, et al. Mature T cells depend on signaling through the IKK complex. Immunity (2003) 19:377-89. doi:10.1016/S10747613(03)00237-1

111. Jimi E, Strickland I, Voll RE, Long M, Ghosh S. Differential role of the transcription factor NFkappaB in selection and survival of $\mathrm{CD} 4+$ and $\mathrm{CD} 8+$ thymocytes. Immunity (2008) 29:52337. doi:10.1016/j.immuni

112. Guo R, Wan CK, Carpenter JH, Mousallem T, Boustany RM, Kuan CT, et al. Synergistic control of $\mathrm{T}$ cell development and tumor suppression by diacylglycerol kinase alpha and zeta. Proc Natl Acad Sci U S A (2008) 105:11909-14. doi:10.1073/pnas.0711856105

113. Gorentla BK, Wan CK, Zhong XP. Negative regulation of mTOR activation by diacylglycerol kinases. Blood (2011) 117:4022-31. doi:10.1182/blood-2010-08300731

114. Matsuda JL, Mallevaey T, Scott-Browne J, Gapin L. CD1d-restricted iNKT cells, the "Swiss-Army knife" of the immune system. Curr Opin Immunol (2008) 20:358-68. doi:10.1016/j.coi.2008.03.018

115. Elewaut D, Shaikh RB, Hammond KJ, De Winter H, Leishman AJ, Sidobre S, et al. NIK-dependent RelB activation defines a unique signaling pathway for the development of $V$ alpha 14i NKT cells. $J$ Exp Med (2003) 197:1623-33. doi:10.1084/jem.20030141

116. Sivakumar V, Hammond KJ, Howells N, Pfeffer K, Weih F. Differential requirement for Rel/nuclear factor kappa B family members in natural killer $\mathrm{T}$ cell development. $J$ Exp Med (2003) 197:1613-21. doi:10.1084/jem.20022234

117. Stanic AK, Bezbradica JS, Park JJ, Van Kaer L, Boothby MR, Joyce S. Cutting edge: the ontogeny and function of Va14Ja18 natural $\mathrm{T}$ lymphocytes require signal processing by protein kinase $\mathrm{C}$ theta and NF-kappa B. J Immunol (2004) 172:4667-71.

118. Shen S, Chen Y, Gorentla BK, Lu J, Stone JC, Zhong XP. Critical roles of RasGRP1 for invariant NKT cell development. J Immunol (2011) 187:4467-73. doi:10.4049/jimmunol.1003798

119. Hu T, Gimferrer I, Simmons A, Wiest D, Alberola-Ila J. The Ras/MAPK pathway is required for generation of iNKT cells. PLoS ONE (2011) 6:e19890. doi:10.1371/journal.pone.001 9890

120. Shen S, Wu J, Srivatsan S, Gorentla BK, Shin J, Xu L, et al. Tight regulation of diacylglycerol-mediated signaling is critical for proper invariant NKT cell development. J Immunol (2011) 187:2122-9. doi:10.4049/jimmunol.1100495

121. Zhong XP, Hainey EA, Olenchock BA, Jordan MS, Maltzman JS, Nichols KE, et al. Enhanced $\mathrm{T}$ cell responses due to diacylglycerol kinase zeta deficiency. Nat Immunol (2003) 4:882-90. doi:10.1038/ni958

122. Olenchock BA, Guo R, Carpenter $\mathrm{JH}$, Jordan $\mathrm{M}$, Topham MK, Koretzky GA, et al. Disruption of diacylglycerol metabolism impairs the induction of $\mathrm{T}$ cell anergy. Nat Immunol (2006) 7:1174-81. doi:10.1038/ni1400

123. Metzger TC, Anderson MS Control of central and peripheral tolerance by Aire. Immunol Rev (2011) 241:89-103. doi:10.1111/j.1600065X.2011.01008.x

124. Xing Y, Hogquist KA. Tcell tolerance: central and peripheral. Cold Spring Harb Perspect Biol (2012) 4:4 doi:10.1101/cshperspect.a006957

125. Schwartz RH. T cell anergy. Annu Rev Immunol (2003) 21:305-34. doi:10.1146/annurev.immunol. 21.120601.141110

126. Powell JD. The induction and maintenance of $\mathrm{T}$ cell anergy. Clin Immunol (2006) 120:239-46. doi:10.1016/j.clim.2006.02.004

127. Fathman CG, Lineberry NB. Molecular mechanisms of CD4+ T-cell anergy. Nat Rev Immunol (2007) 7:599-609. doi:10.1038/nri2131

128. Chappert P, Schwartz RH. Induction of $\mathrm{T}$ cell anergy: integration of environmental cues and infectious tolerance. Curr Opin Immunol (2010) 22:552-9. doi:10.1016/j.coi.2010.08.005

129. Macian F, Garcia-Cozar F, Im $\mathrm{SH}$, Horton HF, Byrne MC, Rao A. Transcriptional mechanisms underlying lymphocyte tolerance. Cell (2002) 
109:719-31. doi:10.1016/S00928674(02)00767-5

130. Zha Y, Marks R, Ho AW, Peterson AC, Janardhan S, Brown I, et al. $\mathrm{T}$ cell anergy is reversed by active Ras and is regulated by diacylglycerol kinase-alpha. Nat Immunol (2006) 7:1166-73. doi:10.1038/ni1206-1343a

131. Sanjuan MA, Jones DR, Izquierdo M, Merida I. Role of diacylglycerol kinase alpha in the attenuation of receptor signaling. J Cell Biol (2001) 153:207-20. doi:10.1083/jcb.153.1.207

132. Merino E, Avila-Flores A, Shirai Y, Moraga I, Saito N, Merida I. Lck-dependent tyrosine phosphorylation of diacylglycerol kinase alpha regulates its membrane association in T cells. J Immunol (2008) 180:5805-15.

133. Matsubara $T$, Ikeda $M$, Kiso Y, Sakuma M, Yoshino K, Sakane F, et al. c-Abl tyrosine kinase regulates serum-induced nuclear export of diacylglycerol kinase alpha by phosphorylation at Tyr-218. J Biol Chem (2012) 287:5507-17. doi:10.1074/jbc.M111.296897

134. Baldanzi G, Pighini A, Bettio V, Rainero E, Traini S, Chianale $\mathrm{F}$, et al. SAP-mediated inhibition of diacylglycerol kinase alpha regulates TCRinduced diacylglycerol signaling. J Immunol (2011) 187:5941-51. doi:10.4049/jimmunol.1002476

135. Santos T, Carrasco S, Jones DR, Merida I, Eguinoa A. Dynamics of diacylglycerol kinase zeta translocation in living T-cells. Study of the structural domain requirements for translocation and activity. $J$ Biol Chem (2002) 277:30300-9. doi:10.1074/jbc.M200999200

136. Topham MK, Bunting M, Zimmerman GA, McIntyre TM, Blackshear PJ, Prescott SM. Protein kinase C regulates the nuclear localization of diacylglycerol kinase-zeta. Nature (1998) 394:697-700. doi:10.1038/29337

137. Grakoui A, Bromley SK, Sumen C, Davis MM, Shaw AS, Allen $\mathrm{PM}$, et al. The immunological synapse: a molecular machine controlling $\mathrm{T}$ cell activation. Science (1999) 285:221-7. doi:10. 1126/science.285.5425.221
138. Dustin ML. T-cell activation through immunological synapses and kinapses. Immunol Rev (2008) 221:77-89. doi:10.1111/j.1600065X.2008.00589.x

139. Topham MK, Prescott SM. Diacylglycerol kinase zeta regulates Ras activation by a novel mechanism. J Cell Biol (2001) 152:1135-43. doi:10.1083/jcb.152.6.1135

140. Gharbi SI, Rincon E, AvilaFlores A, Torres-Ayuso P, Almena $\mathrm{M}$, Cobos MA, et al. Diacylglycerol kinase zeta controls diacylglycerol metabolism at the immunological synapse. Mol Biol Cell (2011) 22:4406-14. doi:10.1091/mbc.E11-03-0247

141. Geiger B, Rosen D, Berke G. Spatial relationships of microtubuleorganizing centers and the contact area of cytotoxic $\mathrm{T}$ lymphocytes and target cells. J Cell Biol (1982) 95:137-43. doi:10.1083/jcb.95.1.137

142. Kupfer A, Dennert G, Singer SJ. Polarization of the Golgi apparatus and the microtubuleorganizing center within cloned natural killer cells bound to their targets. Proc Natl Acad Sci U S A (1983) 80:7224-8. doi:10.1073/pnas.80.23.7224

143. Martin-Cofreces NB, RoblesValero J, Cabrero JR, Mittelbrunn $\mathrm{M}$, Gordon-Alonso M, Sung $\mathrm{CH}$, et al. MTOC translocation modulates IS formation and controls sustained $\mathrm{T}$ cell signaling. J Cell Biol (2008) 182:951-62. doi:10.1083/jcb.200801014

144. Quann EJ, Merino E, Furuta $T$, Huse M. Localized diacylglycerol drives the polarization of the microtubuleorganizing center in $\mathrm{T}$ cells. Nat Immunol (2009) 10:627-35. doi:10.1038/ni.1734

145. Quann EJ, Liu X, Altan-Bonnet $G$, Huse M. A cascade of protein kinase $\mathrm{C}$ isozymes promotes cytoskeletal polarization in T cells. Nat Immunol (2011) 12:647-54. doi:10.1038/ni.2033

146. Alonso R, Mazzeo C, Merida I, Izquierdo M. A new role of diacylglycerol kinase alpha on the secretion of lethal exosomes bearing Fas ligand during activation-induced cell death of $\mathrm{T}$ lymphocytes.
Biochimie (2007) 89:213-21. doi:10.1016/j.biochi.2006.07.018

147. Alonso R, Mazzeo C, Rodriguez MC, Marsh M, Fraile-Ramos A, Calvo V, et al. Diacylglycerol kinase alpha regulates the formation and polarisation of mature multivesicular bodies involved in the secretion of Fas ligand-containing exosomes in T lymphocytes. Cell Death Differ (2011) 18:1161-73. doi:10. 1038/cdd.2010.184

148. Williams MA, Holmes BJ, Sun JC, Bevan MJ. Developing and maintaining protective $\mathrm{CD} 8+$ memory T cells. Immunol Rev (2006) 211:146-53. doi:10.1111/j.01052896.2006.00389.x

149. Harty JT, Badovinac VP. Shaping and reshaping $\mathrm{CD} 8+$ T-cell memory. Nat Rev Immunol (2008) 8:107-19. doi:10.1038/nri2251

150. Zhang N, Bevan MJ. CD8(+) $T$ cells: foot soldiers of the immune system. Immunity (2011) 35:161-8. doi:10. 1016/j.immuni.2011.07.010

151. Shin J, O'Brien TF, Grayson JM, Zhong XP. Differential regulation of primary and memory CD8 $\mathrm{T}$ cell immune responses by diacylglycerol kinases. $J$ Immunol (2012) 188:2111-7. doi:10.4049/jimmunol.1102265

152. Araki K, Turner AP, Shaffer VO, Gangappa S, Keller SA, Bachmann MF, et al. mTOR regulates memory CD8 T-cell differentiation. Nature (2009) 460:108-12. doi:10.1038/nature08155

153. Rao RR, Li Q, Odunsi K, Shrikant PA. The mTOR kinase determines effector versus memory $\mathrm{CD} 8+\mathrm{T}$ cell fate by regulating the expression of transcription factors T-bet and Eomesodermin. Immunity (2010) 32:67-78. doi: 10.1016/j.immuni.2009.10.010

154. Riese MJ, Grewal J, Das J, Zou T, Patil V, Chakraborty AK, et al. Decreased diacylglycerol metabolism enhances ERK activation and augments CD8+ $\mathrm{T}$ cell functional responses. $J$ Biol Chem (2011) 286:5254-65. doi:10.1074/jbc.M110.171884

155. Prinz PU, Mendler AN, Masouris I, Durner L, Oberneder R, Noessner E. High DGK-alpha and disabled MAPK pathways cause dysfunction of human tumor-infiltrating $\mathrm{CD} 8+\mathrm{T}$ cells that is reversible by pharmacologic intervention. $J$ Immunol (2012) 188:5990-6000. doi:10.4049/jimmunol.1103028

156. Abraham SN, St John AL. Mast cell-orchestrated immunity to pathogens. Nat Rev Immunol (2010) 10:440-52. doi:10.1038/nri2782

157. Rodewald HR, Feyerabend TB. Widespread immunological functions of mast cells: fact or fiction? Immunity (2012) 37:13-24. doi:10.1016/ j.immuni.2012.07.007

158. Olenchock BA, Guo R, Silverman MA, Wu JN, Carpenter JH, Koretzky GA, et al. Impaired degranulation but enhanced cytokine production after Fc epsilonRI stimulation of diacylglycerol kinase zetadeficient mast cells. $J$ Exp Med (2006) 203:1471-80. doi:10.1084/jem.20052424

159. Liu CH, Machado FS, Guo R, Nichols KE, Burks AW, Aliberti JC, et al. Diacylglycerol kinase zeta regulates microbial recognition and host resistance to Toxoplasma gondii. J Exp Med (2007) 204:781-92. doi:10.1084/jem.20061856

Conflict of Interest Statement: The authors declare that the research was conducted in the absence of any commercial or financial relationships that could be construed as a potential conflict of interest.

Received: 02 April 2013; paper pending published: 22 April 2013; accepted: 19 June 2013; published online: 04 July 2013. Citation: Krishna $S$ and Zhong X-P (2013) Regulation of lipid signaling by diacylglycerol kinases during T cell development and function. Front. Immunol. 4:178. doi: 10.3389/fimmu.2013.00178

This article was submitted to Frontiers in T Cell Biology, a specialty of Frontiers in Immunology.

Copyright $\odot 2013$ Krishna and Zhong. This is an open-access article distributed under the terms of the Creative Commons Attribution License, which permits use, distribution and reproduction in other forums, provided the original authors and source are credited and subject to any copyright notices concerning any third-party graphics etc. 